\title{
Cold Crucible Induction Melter Technology: Results of Laboratory Directed Research and Development
}

D. Gombert

J. G. Richardson

September 2001

Idaho National Engineering and Environmental Laboratory Bechtel BWXT Idaho, LLC 


\title{
Cold Crucible Induction Melter Technology: Results of Laboratory Directed Research and Development
}

\author{
Dirk Gombert \\ John G. Richardson
}

September 2001

\section{Idaho National Engineering and Environmental Laboratory Idaho Falls, Idaho 83415}

Prepared for the

U.S. Department of Energy

Assistant Secretary for Environmental Management

Under DOE Idaho Operations Office

Contract DE-AC07-99ID13727 


\begin{abstract}
This report provides a review of cold crucible induction melter (CCIM) technology and presents summaries of alternatives and design issues associated with major system components. The objective in this report is to provide background systems level information relating to development and application of cold crucible induction-heated melter technology for radiological waste processing. Included is a detailed description of the bench-top melter system at the V. G. Khlopin Radium Institute currently being used for characterization testing
\end{abstract}




\section{CONTENTS}

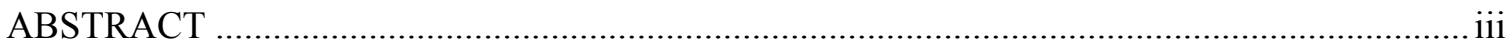

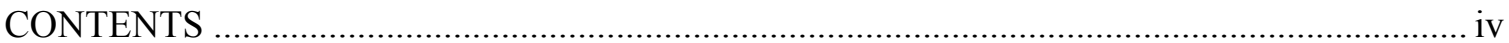

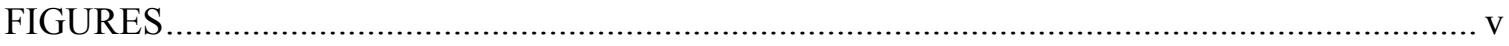

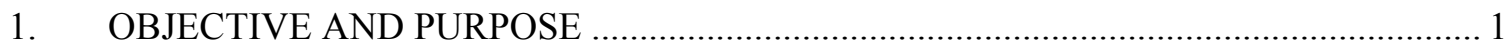

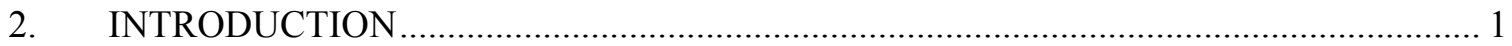

3. SYSTEM DESIGN AND DESCRIPTION OF MAJOR COMPONENTS ........................ 1

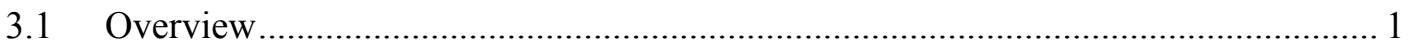

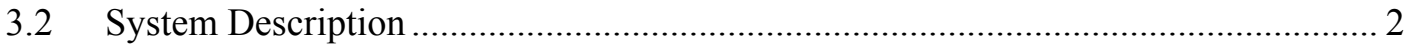

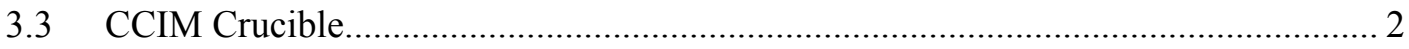

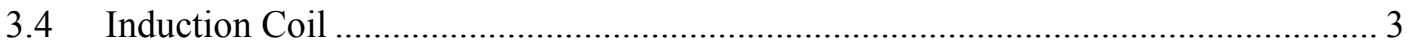

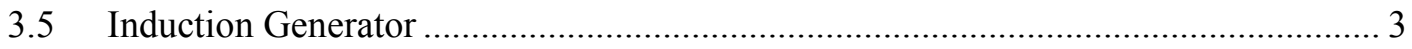

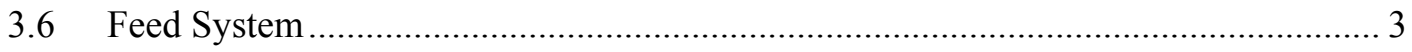

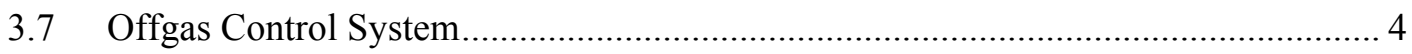

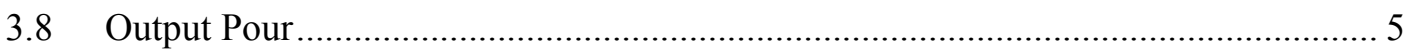

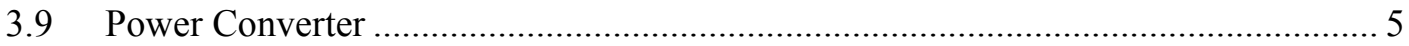

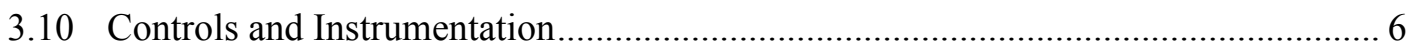

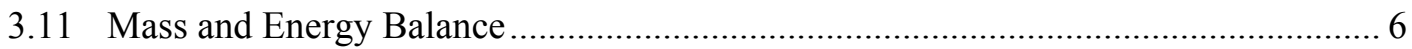

4. DESIGN ISSUES AND ALTERNATIVES …............................................................ 7

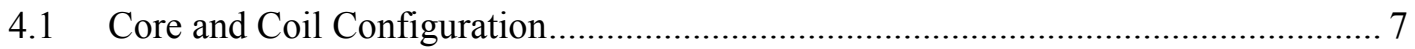

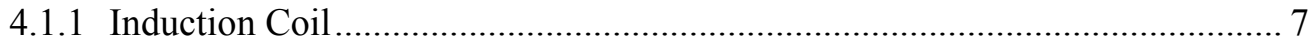

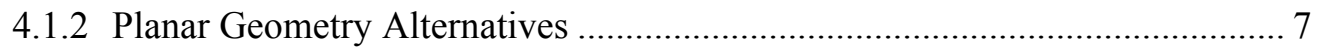

4.1.3 Crucible Axial Geometry .............................................................................. 9

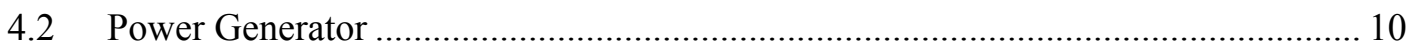

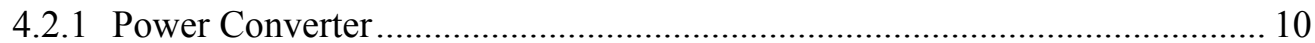

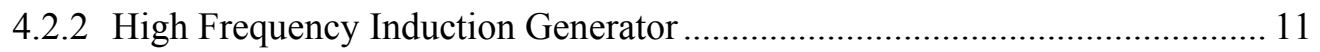

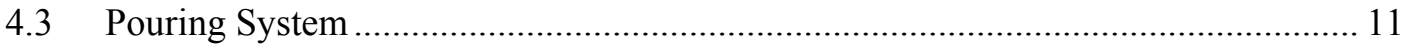




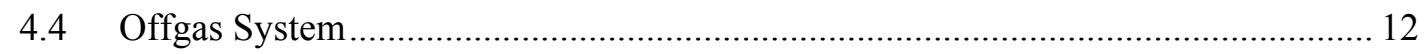

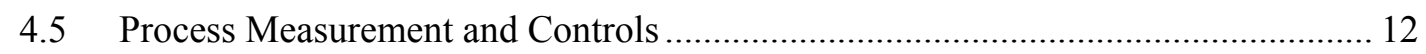

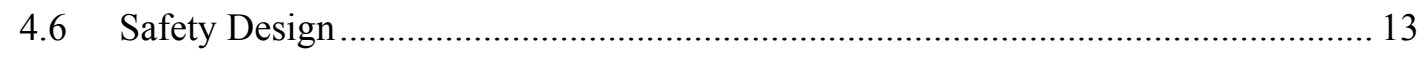

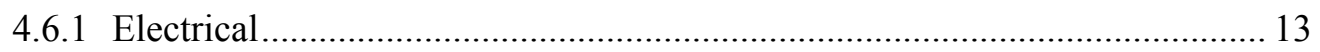

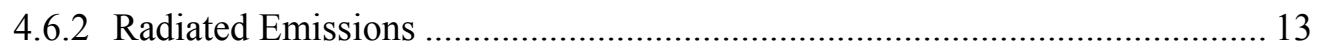

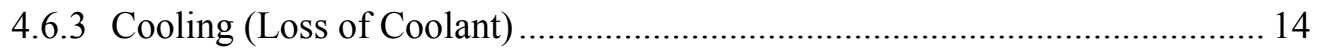

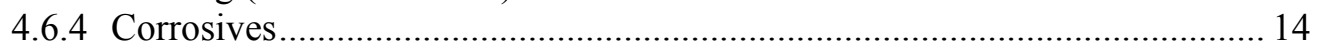

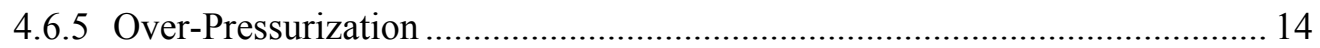

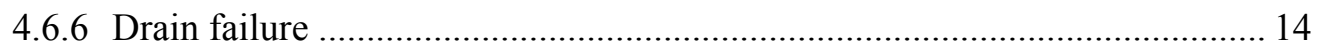

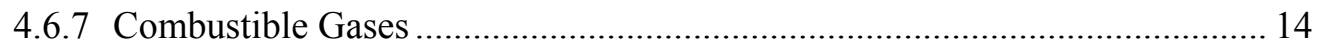

5. PROCESS DESIGN FOR DEVELOPMENT AND TESTING .................................... 15

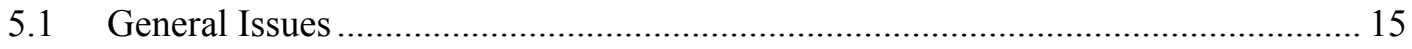

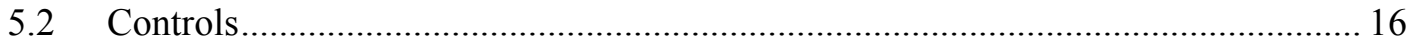

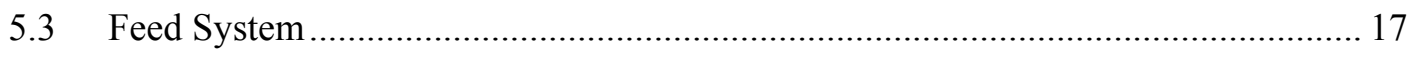

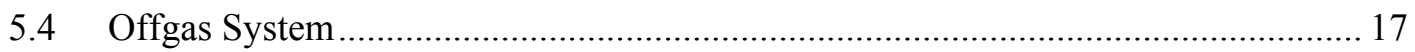

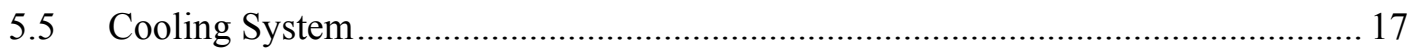

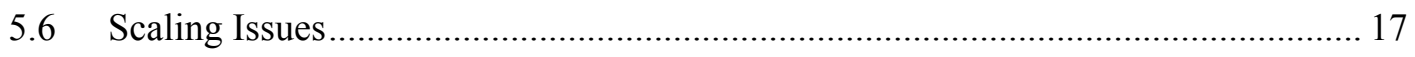

6. CURRENT TESTING PROGRAM AND PRELIMINARY RESULTS ............................. 18

APPENDIX A: SUMMARY OF TRIP TO VISIT RADON AND KRI …................................ A-1

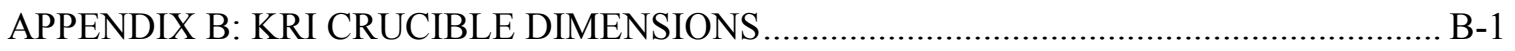

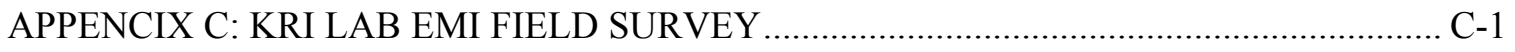

APPENDIX D: SCHEMATIC OF LAMP GENERATOR AND CCI INDUCTOR COUPLING

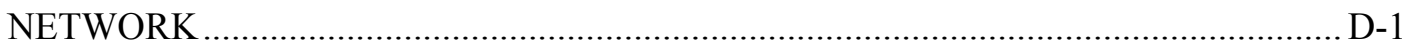

\section{FIGURES}

Figure 1. Cold Crucible Induction Melter System............................................................... 2

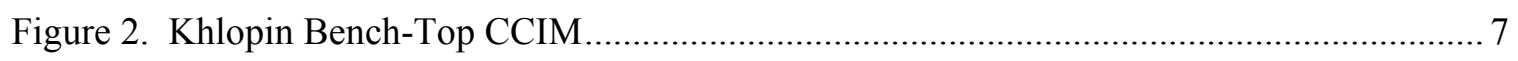

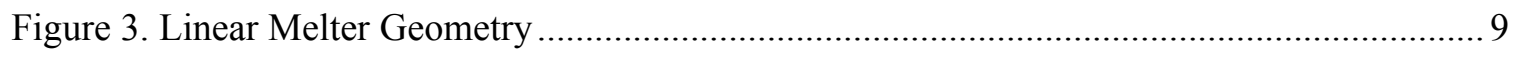

Figure 4. Tapered and Symmetric Crucible Geometries....................................................... 10 


\section{OBJECTIVE AND PURPOSE}

The purpose of this report is to briefly review the theory of cold crucible induction melter (CCIM) technology and provide brief summaries of alternatives and design issues associated with major system components. The data contained herein derives from various academic and commercial sources including detailed discussions with staff at the Moscow Scientific and Industrial Association in Moscow, Russia, and the V. G. Khlopin Radium Institute (KRI) in St. Petersburg. The objective in this report is to provide the reader with an understanding of the issues associated with development and application of cold crucible induction-heated melter technology to waste processing, including currently completed work to date and near term laboratory bench-top tests of various physical and electrical configurations.

\section{INTRODUCTION}

The current technology in use in the USA and Europe for converting highly radioactive wastes into glass for final disposal is based on joule-heated melting. A joule-heated melter operates by passing electricity between water-cooled electrodes submerged in a molten pool of glass in a brick-lined chamber. This design is inherently limited by the susceptibility to corrosion and melting of the bricks and metal electrodes. In addition, the glass chemistry must be carefully controlled or it can increase the materials problems and lead to the electrical short-circuiting and glass leaks that have caused failures in test melters. A radically different design that has been in use for several years in Russia for a different kind of wastes is called a cold-crucible induction melter or CCIM. The CCIM design eliminates many of the materials and operating limitations inherent in the joule-heated melter. The cold-crucible design is smaller, less expensive, and generates much less waste for ultimate disposal. It should also allow a much more flexible glass chemistry, which will be crucial if the heterogeneous wastes at the INEEL are to be processed.

In contrast to the joule-heated melter, the CCIM design melts glass by induction inside of a water-cooled high-frequency electrical coil. Similar to the heating of food in a microwave oven, the glass absorbs energy from an electrical field caused by the coil without ever actually touching it. Not only does the coil not touch the molten glass, the melt is contained in a crucible that is water cooled. The cooling creates a coating of solidified glass that protects the crucible and contains the molten pool, eliminating the need for any refractory. Change out of the corroded refractories and electrode materials from a failed melter results in significant radiation exposure and lost operating time during maintenance, as well as generating voluminous highly radioactive wastes. Much of this is eliminated with the CCIM design.

\section{SYSTEM DESIGN AND DESCRIPTION OF MAJOR COMPONENTS}

\subsection{Overview}

Electromagnetic induction is a method of heating conductive materials that relies on electrical currents that are induced into the material being heated. These currents, called eddy currents, heat the material. A generic electromagnetic induction furnace, or melter, consists of a few major process components: an enclosure to physically contain the material being melted, an induction coil, and a high-frequency alternating current power source called an induction generator.

Another common component is a power supply or power conversion system that conditions commercial 50 or 60 Hertz line power to meet the input requirements of the high frequency power source. A cold crucible induction melter physically contains the melt material within a 
structure of cooling coils, wherein the cooled material itself forms a crucible. An offgas treatment system is required for applications where hazardous or radioactive volatiles may be released. In addition, continuous process CCIM systems require a means to pour the resulting melt into storage or transport containers. An integrated control and engineered safety system will insure safety and melt quality.

\subsection{System Description}

Figure 1 is a generic block diagram of a cold crucible induction heated melter system. Note that there are eight major system components. Each of these components performs a key function, and together they form a system. The system configuration and each of the components perform distinct functions and must respond to certain design requirements to ensure overall system performance.

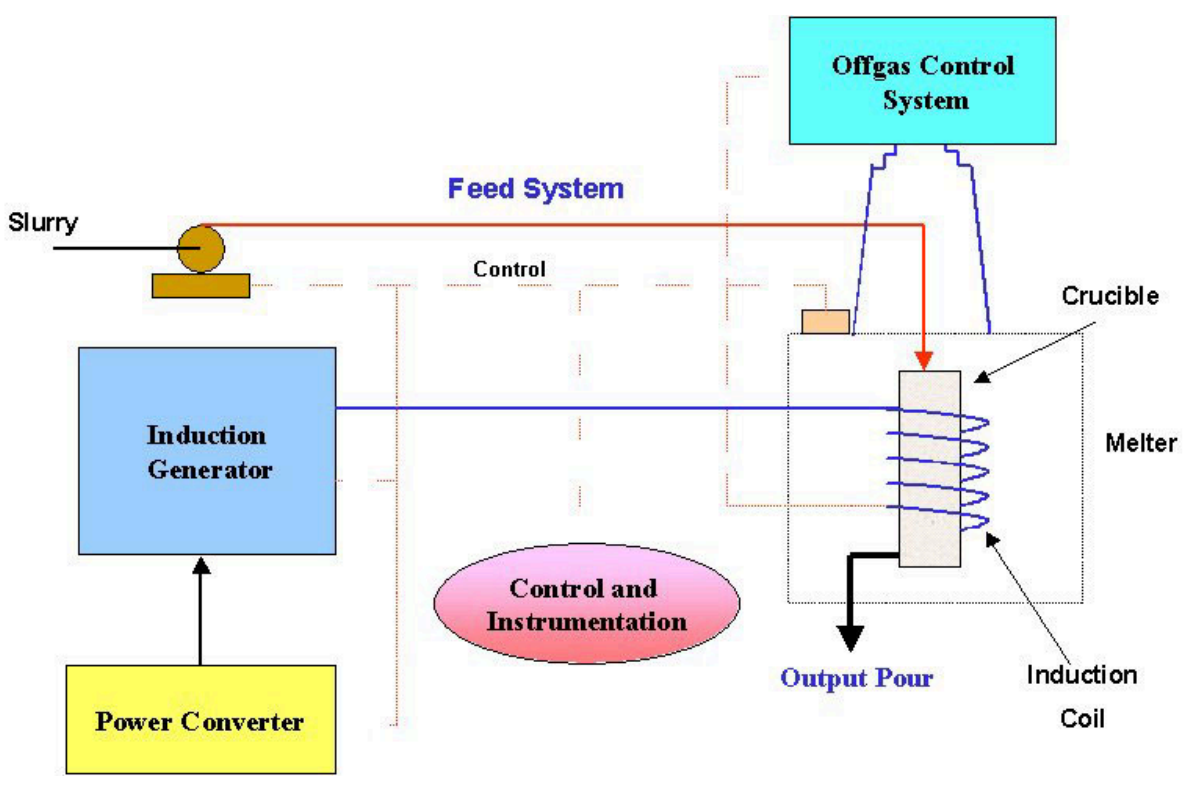

Figure 1. Cold Crucible Induction Melter System

\subsection{CCIM Crucible}

The crucible contains the melt material. In a CCIM melter the crucible consists of a tube-type heat exchanger configured such that an internal volume is created. The can be a simple rightcylinder, oval, or a more complex shape such a cruciform. The material to be melted is placed inside the crucible assembly. As heating begins, the coolant removes enough heat such that the material directly adjacent to the wall remains solid forming a "skull," or containment that encapsulates the melt around its periphery and on the bottom.

There are a number of crucible design issues. The crucible must be able to contain the waste feed prior to initiation of melting as well as the molten pool during processing. It must allow the varying magnetic field associated with eddy current heating to pass through in a known and predictable manner from the external induction coil to the waste matrix inside the crucible. It is desirable that electrical energy losses due to the heat exchanger be as small as possible. The crucible must remove heat rapidly enough to maintain a solid glass layer (or unmelted feed 
particulate) at the external surface of the melt. The coiling coils must also preserve their own integrity by maintaining their surface temperature below the material melting point. Lastly, the coil materials must be corrosion resistant to the feed material on top of the glass (liquid, slurry, paste or solids) as well as gases and condensate that contact the crucible in the plenum over the waste. Corrosion is reduced due to the relatively cool crucible surface, but the materials of construction must withstand gases that may be highly acidic or basic, as well containing free halogens like fluoride and chloride.

\subsection{Induction Coil}

As noted above, the induction coil component is placed outside the crucible. In fact, the crucible is surrounded by the coil. The purpose of the induction coil is to transform the output of the high frequency generator into a varying magnetic field. The magnetic flux passes through the crucible and produces eddy currents in the conductive contents inside the crucible. The eddy currents are dissipated by the electrical resistivity of the material causing joule- heating and melting.

Design of an induction coil is not trivial. It must be configured (diameter, number and spacing of turns) to maximize efficiency of energy transfer from the generator to the melt. The design is constrained by the physical dimensions of the crucible, the electrically conductive properties and volume of the melt, the desired thermal profile of the melt, and the output electrical properties of the generator itself. Because of the large amount of energy conducted through the coil and the electrical resistivity of common conductive materials used to make the coil such as copper, a coil as part of a CCIM system will likely require active thermal cooling. Induction coils also require a mechanical support structure due to both the size (weight) and active cooling required.

\subsection{Induction Generator}

The induction generator is typically rated in terms of maximum power output and frequency(s) of operation. Its purpose is to generate high frequency alternating current to drive the induction coil. Typical frequencies for CCIM application range from $100 \mathrm{kHz}$ to $2 \mathrm{MHz}$, with power levels from 20 kilowatts to several megawatts. For this frequency and power range, designs are based on either metal oxide semiconductor field effect transistor (MOS FET) power devices or vacuum transmitting tubes. Both transmitting tubes and MOS FET's dissipate significant power for all circuit configurations, and active cooling will be required. Air is commonly used in the broadcast industry but water has a much higher specific heat and is likely to prove superior. However, a recirculating high-purity water system may be required because common utility water is somewhat conductive and will lower the quality factor (Q) of the induction coil.

\subsection{Feed System}

Cold crucible melters used in Russia and France receive calcined (dry) or paste (moist) feed materials to maximize the use of the inductive energy for melting glass. Current high-level waste operations in the United States at the Savannah River Site, SC and West Valley, NY feed liquid slurries to joule-heated melters (JHM). This departure in operational philosophy is driven by offgas and volatility concerns, and complexity of design. Some waste constituents, notably cesium, ruthenium, and lead are quite volatile at common melter operating temperatures, causing a significant fraction of these materials to partition to the offgas system. Recycling the materials caught in the offgas treatment system to the melter is only partially effective because a significant fraction is revaporized and ends up back in the scrub solution. Disposal of the liquid scrub waste requires that it must be treated to reduce the leachability of hazardous components (lead) to 
disposal standards. This is further complicated by the radioactive constituents (cesium and ruthenium). Still, this is the treatment and disposal scheme employed in Europe.

By feeding an aqueous slurry onto the melt, a boiling layer can be maintained over a transitional layer of drying feed solids on top of the molten glass itself. Materials volatilized from the molten glass must pass upward through this "cold cap" which causes condensation and reflux back into the melt, thereby maximizing retention of these species in the glass. Cold cap operation can reduce cesium losses from several tens of percent to just $2-3 \%$, but the added cost is the melter heat required to vaporize all of the waste liquids. This additional heat load is reported to cause a reduction in melter throughput (derating) by $50 \%$ or more versus feeding calcined materials. Offsetting this reduction in melter capacity is the fact that the additional equipment needed to dry or calcine the liquid waste is avoided in the American design. This unit operation is particularly problematic for caustic wastes, which congeal and do not flow well as they evaporate. Though acidic wastes such as the sodium bearing waste at the INEEL could be evaporated significantly to reduce the added heat load on the melter, the current plan is to feed a liquid waste. Thus, under the current operating philosophy, the feed system for a CCIM to be used in the USA, would be entirely different from those used in Europe, and the CCIM design to be used in this country would be significantly derated.

The waste feed must also be accurately metered and mixed with a reducing agent (probably sugar) to promote reduction of nitrate to nitrogen and glass formers (either in chemical form or as frit) added to yield the final vitrified waste form. This mixing of constituents is not a trivial process; the quality assurance program to assure consistent melter feed at Savannah River is a large and complex operation.

\subsection{Offgas Control System}

Offgas control for thermal treatment has been the subject of extensive study and development. Key issues are acid gases, mercury, condensation of semi-volatile alkali metals, organic byproducts such as products of incomplete combustion (PICs) notably dioxins, and a variety of lower concentration radioactive and hazardous elements including cesium, ruthenium, iodine, lead, and cadmium. Offgas from a CCIM is not expected to be significantly different from a JHM operated at the same temperature with the same feed. However, one of the potential operating advantages for the CCIM is the capability to melt glasses at significantly higher temperatures. Though the practical benefits in increased feed rate or greater solubility of refractory oxides such as alumina and zirconia have not been quantified, glass melts have been completed in CCIMs at up to $2000^{\circ} \mathrm{C}$. Offsetting these potential advantages is the higher temperature exacerbating the volatility of problematic constituents.

Operation of a glass melter with a cold cap can drastically reduce offgas temperature, even though the melt temperature is quite high. Personnel from the Radon facilities outside Moscow report an offgas temperature of just over $100^{\circ} \mathrm{C}$ when processing a sodium nitrate waste dried to a paste containing 20-25 wt\% moisture. At these temperatures, the primary issue would be keeping the gases hot enough to keep acid gases from condensing and refluxing on the upper part of the cold-crucible and plenum surfaces. Radon personnel report a cesium loss of only about $1-3 \%$. Offgas is filtered through a $<100$ micron metal mesh, followed by a HEPA grade filter. The essentially particle free gases are then scrubbed with nitric acid to remove NOx, with the residual NOx reduced over a vanadium impregnated catalyst.

If supplemental plenum heaters were employed to accelerate evaporation of the liquid feed as is typical in JHM applications, offgases could be several hundred degrees higher and any threat of 
aqueous condensation problems would be eliminated. This increased temperature would be expected to mirror the results seen with JHM experience.

\subsection{Output Pour}

Joule-heated melters currently in use for HLW processing pour glass in a fashion similar to a teapot, with molten glass exiting from a level near the bottom of the pool, up through a heated pour spout, and dropping into a receiving canister. This type of design is also possible with a CCIM, but this is an area where innovation could make significant improvements. The teapot design allows good control over melt level, but the concept has had to overcome several challenges. Without sufficient heating of the spout area, strings of glass can form due to rapid cooling of the high surface tension falling stream. With wear of the point where the glass disengages from the melter, the glass can wick back on the surface of the pour spout instead of separating cleanly to pour into the canister. These phenomena can plug the pour spout and halt operations until the required maintenance is complete.

The CCIMs seen in Russia are typically operated in a semi-batch mode, and glass is removed by literally tipping the melter and decanting, or by using a water-cooled metal plug valve. Experimental melters range from the current KRI unit that melts a starting charge and is then cooled to remove a solid block, to slightly larger units at the scientific institutes that are poured from the top either by tipping or overflow. Note that pouring from the top precludes continuous feed, unless an underflow weir is used to separate the feed chamber from the pouring or fining chamber. A water cooled underflow weir design in a CCIM has also been built by the Russians as shown in Figure 2 of Appendix A. The French designs appear to use water-cooled gate valves to control pouring from a bottom outlet.

The Russian design philosophy seems to emphasize smaller high-frequency units, versus the French approach using larger diameter, lower-frequency melters. With the lower inventory in process in the Russian units, it may not be practical to operate in a continuously pouring mode, and semi-batch operation with a cycling melt depth may be most advisable. Without refractory to consider, the consequences of thermal shock are drastically reduced. A trade study is probably warranted to evaluate the relative benefits of semi-batch operation with a small inventory versus continuous pouring with a much larger molten inventory. Beyond the operational aspects are the QA issues around small versus large batches, and the safety aspects due to the consequences of catastrophic failure.

\subsection{Power Converter}

The generator requires a direct current voltage supply. The key components of the power conversion system are the voltage converter and rectifier, filters, regulator, and control and protection circuitry. Some of these components may be combined in the same physical hardware. The capacity of the supply must exceed the output of the induction generator because of inefficiencies in the generation of RF power. This excess capacity requirement may be as high as $100 \%$. For a lamp tube configuration, the voltage requirement will typically be between 1000 and 3000 Volts. For a MOS FET based amplifier the voltage requirements will be an order of magnitude lower, on the order of hundreds of volts. Note that for the latter case the current will be proportionately higher. For most designs the voltage supply must be maintained within a certain accuracy and likely must be programmable over a range of values.

Design issues include 1) power and voltage output requirements (including the requirement for excess capacity), 2) specification of accuracy of programmed value, regulation, and purity of 
output, 3) heat dissipation, 4) engineered safety system including interlocks and crowbar circuit protection, 5) reliability, and 6) the necessity of providing backup power during interruptions of commercial power.

\subsection{Controls and Instrumentation}

The controls and instrumentation element of a CCIM system serves three functions: 1) create and maintain temperature within the melt to a specified tolerance during steady state operation; 2) supply temperature and other information to operators and to a system that records operating parameters during operation, 3 ) provide the means for control of the process during non steadystate operation such as startup, shutdown, and melt pour, and 4) acquire and transmit data necessary for operation of engineered system-level safety systems.

Control of a CCIM system may be done manually or automatically. The design of automated control system requires the steady state values and dynamic responses of the power supply, RF generator, and melter itself along with the associated sensors.

\subsection{Mass and Energy Balance}

The primary design variable for both mass and heat balances is operating temperature. If the potential benefits of higher temperature operation including higher throughput and higher waste loading outweigh the potential disadvantage of higher volatility, the offgas treatment system for the CCIM could be made somewhat more complex. Recycle of offgas scrub solution back to the melter could also be more difficult. Current operation at the Defense Waste Processing Facility (DWPF) returns a scrub waste stream comparable in size to the feed going to the melter. The scrub solution is concentrated in an evaporator for eventual feed back to the melter. A higher melter operating temperature could reduce the potential for effective recycle, and the scrub waste stream may have to be treated by some other method of immobilization such as grout. The ramifications of higher temperature operation on the overall material balance should certainly be evaluated in an experimental CCIM.

The energy balance with a CCIM is drastically different from a JHM. First the efficiency of the energy deposition in the melt is a function of the both the power source, which has to convert line voltage to that required for the high frequency generator for induction, and the coupling efficiency of the high frequency coil with a relatively low-conductivity glass melt. In a JHM, essentially all of the applied power is dissipated directly in the glass melt. Second, in a JHM, the melt is surrounded by refractory brick and several layers of low-density silica insulating board. The outer metal containment may be water-cooled, but the total heat transfer is drastically reduced by the multiple insulating layers. In the CCIM, there is a $1000+{ }^{\circ} \mathrm{C}$ temperature gradient across a 2-5 mm layer of solidified glass "cold-skull" between the melt and the water-cooled crucible. This lower energy efficiency is not necessarily a significant cost issue, but the energy balance, thermal profile, and operational energy deposition model must be understood to do detailed design. This knowledge should be a primary focus in laboratory and pilot-scale development of the CCIM technology. 


\section{DESIGN ISSUES AND ALTERNATIVES}

\subsection{Core and Coil Configuration}

\subsubsection{Induction Coil}

The cooled crucible and induction coil are two key components of a CCIM system. In their simplest form they consist of a cylindrical single pass heat exchanger surrounded by a linear solenoid inductor. Below is a photograph of such a system currently being used at the V. G. Khlopin Radium Institute (KRI) in St. Petersburg, Russia for glass properties studies. This bench top system is approximately $9 \mathrm{~cm}$ in diameter and $40 \mathrm{~cm}$ tall. The six-turn coil has an internal diameter of approximately $12 \mathrm{~cm}$. Note that both the crucible and the induction coil are cylindrical.

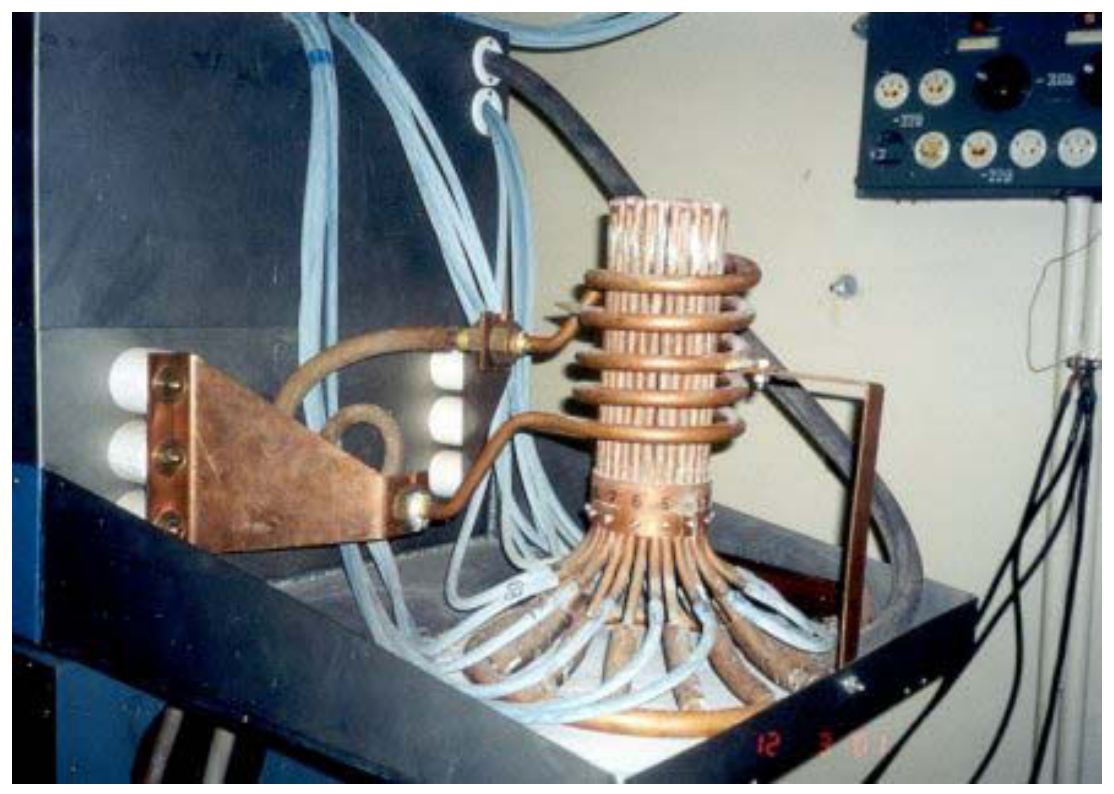

Figure 2. Khlopin Bench-Top CCIM

There is strong interdependence between the configuration of the crucible containing the waste/melt and the induction coil that introduces energy into the crucible. Therefore, both the crucible and the induction coil configurations must be evaluated during design, including various physical and electrical alternatives, considering advantages and disadvantages of each.

\subsubsection{Planar Geometry Alternatives}

Conventional induction melters are designed as a right-cylinder with a circular cross section. The melter may be oriented horizontally or vertically. The associated induction coil is also cylindrical with a fixed diameter larger than the crucible. Conventional designs have a uniform spacing between the solenoid induction coil and the exterior walls of the crucible. Equal spacing between all turns of the coil is also typical. There are two reasons why a cylindrical geometry has been adopted as the convention. First, the cylinder exhibits a very low ratio of surface area to volume relative to other geometries, reducing heat loss. Second and perhaps more important, the cylindrical shape simplifies calculations and most closely matches the geometry of inductors for 
which much theoretical work has been done. In addition, fabrication of such an assembly does not require changes in radius of curvature and the specialized mandrel or other fabrication jigs for the induction coil and in some cases the crucible itself that would be necessary for more exotic cross sections.

There are disadvantages of cylindrical induction melters. Approximately $86 \%\left(1-1 / \mathrm{e}^{2}\right)$ of the energy transferred by the induction coil is deposited within a certain distance of the surface of the melt. This distance is called the skin depth, and is defined as $\delta$ :

$$
\delta=5^{*} 10^{3}(\rho / \mu \mathrm{f})^{1 / 2}
$$

where $\rho$ is electrical resistivity in ohm-cm of the melt, $\mu$ is magnetic permeability of the melt, and $f$ is the frequency of the energy being applied in Hertz. For a large melter crucible containing relatively low conductivity (high resistivity) material, a disproportionate amount of energy is deposited near the surface of the melt. Scientists at the Moscow Scientific and Industrial Association in Moscow, Russia have empirically modeled energy transfer for such melters and have found they can obtain electrical energy transfer efficiencies of $80 \%$ by meeting the following criteria:

$$
\begin{gathered}
3<\left[\mathrm{D}_{\mathrm{c}} /(\delta \sqrt{ } 2)\right]<5 \\
\mathrm{D}_{\mathrm{c}} \equiv \text { crucible diameter } \\
\delta \equiv \text { depth of penetration (skin depth) }
\end{gathered}
$$

Note that crucible diameter is constrained by the depth of penetration. In their application, operating at $1.76 \mathrm{MHz}$, this formula restricts melter design to diameters on the order of $5-7 \mathrm{~cm}$. Thus it is desirable that the mean distance from the surface of the crucible to the melt material be minimized. However, one characteristic of a cylindrical geometry is that the mean distance from the side-wall surfaces to the interior of the cylinder is larger than any other geometry, just the opposite of what would be desired for an induction melter application with low conductivity materials.

There are two approaches that can be taken to address this problem. Either the skin depth parameter can be increased or the mean diameter of the melter can be decreased. Decreasing frequency will increase skin depth at the expense of lower efficiency. Electrical conductivity can be increased by additives to the melt such as graphite, carbides, or pieces of metal, but this changes the chemical makeup of the resultant material and may not be desired. However, the mean diameter of the induction melter itself can be reduced in two ways. The first is to reduce the mean distance to the melt by reducing the mean diameter of the cylinder (limiting to smaller diameter as discussed above). The other is to change the shape to a non-cylindrical configuration such as an ellipse or cruciform which exhibit a smaller average distance from the cylinder wall to the melt volume.

There is another tactic that can be applied to this problem. The induction coil can be excited with multiple frequencies such that energy deposition is more evenly applied to the melt. Note that for a cylindrical geometry the volume exceeding a certain skin depth reduces by the square of that depth. Thus, low frequencies (and consequently low efficiencies) can be used to heat the relatively small volume near the centerline of the melter, and higher frequencies can be used at the surface. This does not completely solve the skin depth problem, but it should significantly reduce the slope of the gradient of energy deposition versus distance from the wall. These 
approaches must be evaluated and their relative benefits quantified through modeling and laboratory experimentation

\subsubsection{Crucible Axial Geometry}

Both energy deposition and residence time are affected by the longitudinal geometry of the crucible and the induction coil. Longitudinal, and to some extent radial temperature gradients can be created by varying crucible diameter and/or varying the induced flux along the axis of the melter. There are three basic topologies of axial melter crucible and induction coil geometry to do this: linear, tapered, and symmetric.

A linear geometry melter consists of a crucible of constant diameter along it's length, a cylinder. Fabrication may take advantage of this linear shape. The system may be configured as a linear solenoid, meaning the concentric induction coil is designed with a fixed number of turns per meter. The induced flux is then constant, and for a melt of homogeneous conductivity and magnetic permeability, the induced energy per unit of time will be constant along the length of the crucible. Varying the induced flux by changing the turns per meter over the length of the crucible can be used to apportion energy deposition under those same conditions. This type of configuration is called a gradient solenoid, and may be desirable to optimize output quality, simplify control during dynamic situations such as adding feed material and pouring the removing melt, or to promote mixing by convection and process residence time. Both configurations are illustrated in Figure 3, Linear Melter Geometry.

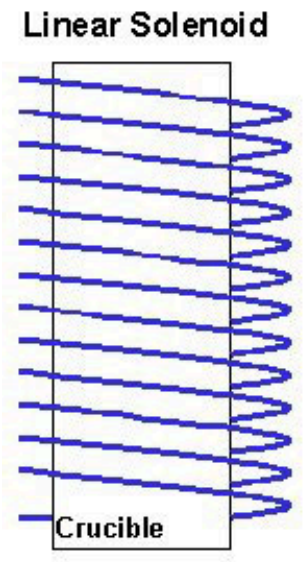

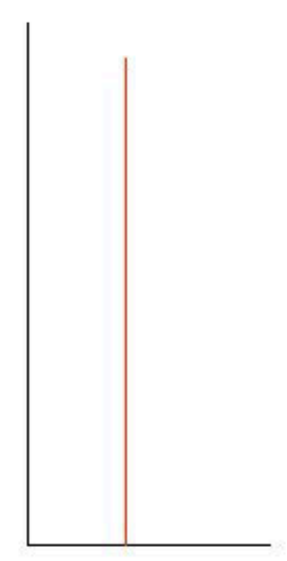

Watts Induced per Meter
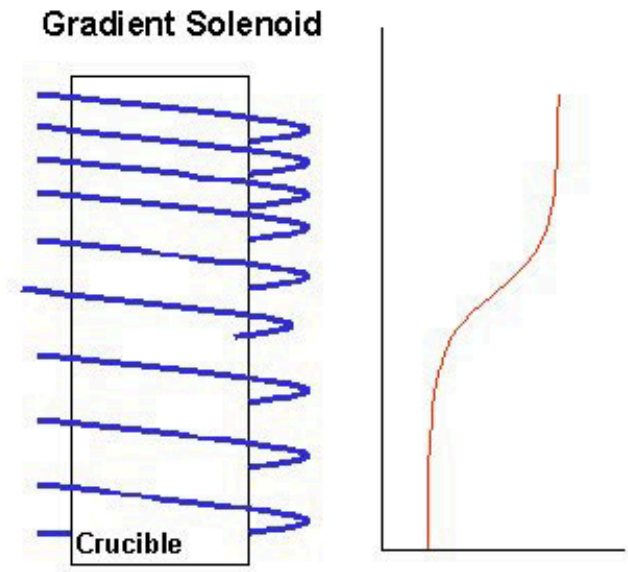

Watts Induced per Meter

Figure 3. Linear Melter Geometry

Skin depth phenomenon also causes non-uniform energy deposition, which can be exploited to drive temperature gradients and convective mixing. Since conductivity changes with temperature, the temperature differences themselves will affect energy deposition. 
Tapered and symmetric melter geometries both have the potential to establish non-uniform deposition of energy, but in addition allow control of physical cross section dimensions and the resulting effects on mixing, transit time, and energy loss. In particular they allow independent control of surface area and volume, including areas at the top and bottom of the crucible. Figure 4 below presents two examples.

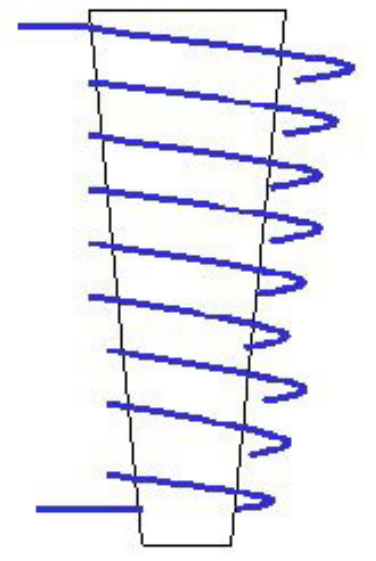

Linear Tapered Geometry

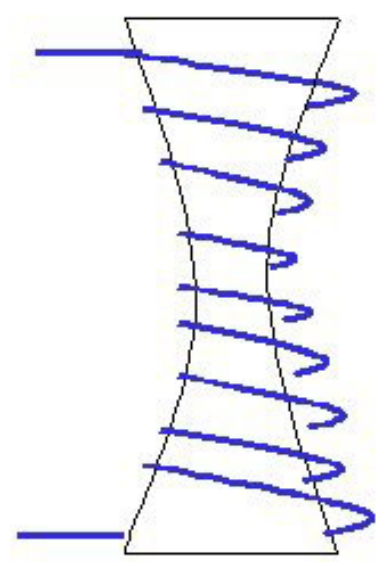

Symmetric Geometry

Figure 4. Tapered and Symmetric Crucible Geometries

There are, of course, varying combinations and permutations of axially symmetrical melter geometries which affect both energy deposition and residence time for a given unit volume. Similarly, there are many additional solenoid configurations that can be used to program energy transfer to the melt. This is just a brief introduction to the possibilities of varying the crucible and coil conformations to modify the temperature profile, mixing characteristics, energy deposition and thermal efficiencies, and residence time versus a simple cylindrical CCIM. Some of these theoretical options will be more problematic to fabricate than their potential operational advantages can justify, but this is a fertile area for study, which may yield better designs and significant intellectual property.

\subsection{Power Generator}

\subsubsection{Power Converter}

The power converter translates commercial line power to voltage necessary to power the induction generator(s) at a sufficiently large current. This entails a process of changing the commercial voltage to that required by the radio induction generator, and then converting the alternating current to direct current. At the same time the value of voltage or limit on current must be controlled for reproducibility and typically also for power control purposes. In addition, there may be a need to guarantee a constant level of the supplied energy to the generator in terms of voltage accuracy, stability, spectral purity, and source impedance.

The KRI melter uses commutation prior to voltage conversion to control power converter output voltage. Rectification (conversion to direct current) is done at the secondary of the converter transformer. Standard U. S. design combines these functions of voltage control and rectification 
into a single multiphase silicon controlled rectifier (SCR) switched bridge rectifier. Both approaches use phase control of the solid state switching as their voltage control scheme. For applications where the induction generator is based on vacuum tube technology, the advantage of the Russian approach is that the commutation is done at lower voltage since these types of vacuum tubes typically require voltages in excess of 1 kilovolt. However, with this approach the commutation will occur at a much higher current requiring devices that can withstand the stress of interrupting a high current feeding a somewhat inductive load. For metal oxide semiconductor field effect transistor (MOS-FET) based induction generators, the U.S system has the advantage of combining control and rectification in a single stage, and quite possibly operating at a moderate voltage and current.

Neither approach has a distinct advantage meeting voltage accuracy and stability requirements of the induction generator if a proper feedback control system is designed. Source impedance is addressed by proper selection and sizing of components and source of power, and also by control system design. There is a tradeoff between spectral purity and some of the other criteria in that higher spectral purity constrains the ability of a power feedback control system to rapidly respond to varying demands of the load. This tradeoff can be made once dynamic process models of production melters are available.

\subsubsection{High Frequency Induction Generator}

A high frequency induction generator converts direct current from the power converter to high frequency alternating current that is subsequently applied to the induction coil. The frequencies vary over a range of $1 \mathrm{kHz}$ to $2 \mathrm{MHz}$. For waste production melter applications it is likely that practical frequencies are in the $100 \mathrm{kHz}$ to $2 \mathrm{MHz}$ range with powers in the 100 's of kilowatts. A typical induction generator is rated in terms of maximum power output (with a specified load) and frequency(s) of operation. For this frequency and power range, designs are based on either on metal oxide semiconductor field effect transistor (MOS-FET) power devices or vacuum transmitting tubes. Both transmitting tubes and MOS-FET's dissipate significant power for all circuit configurations, and active cooling will be required. Air is commonly used in the broadcast industry but water has a much higher specific heat and is likely to prove superior. One problem is that readily available water is somewhat conductive and will lower the quality factor $(\mathrm{Q})$ of the induction coil unless a means is adopted to interrupt the flow on the cooling outlet.

\subsection{Pouring System}

As described above, the pouring systems used in Russian and French CCIM designs use very simple, positive control measures, plug valves, gate valves, or tilt decanting. As a general rule, simple designs are the best, however, moving parts are to be avoided whenever possible in a remote radioactive environment, and the induction melting technique could possibly be extended to the drain.

A smaller diameter cold-crucible could potentially be used as an effective bottom drain. The drain would be inductively heated for draining, and flow would be terminated by turning off the power. Without the inductive current, the normal flow of cold water through the crucible would make it function as a freeze plug. Whether the drain would function constantly or intermittently would be decided based on development work and testing. Thermal cycling, convective wear to the drain, maintenance of the cold skull inside the cold-crucible drain, and reliability of melter level control will all be design considerations. This type of design would essentially eliminate concerns about buildup of noble metals, because they would be constantly purged with a bottom drain. The higher temperature capability of the CCIM should also eliminate liquidus limitations, 
because the drain temperature should be variable to remelt any crystallization due to devitrification in the drain.

\subsection{Offgas System}

Offgas treatment for the CCIM system should not be significantly different from the baseline technology identified for a JHM system. Processing SBW as a liquid with an added organic reducing agent will yield a relatively small offgas stream composed primarily of water, NOx, $\mathrm{SOx}$, and $\mathrm{COx}$, with smaller amounts of $\mathrm{HCl}, \mathrm{HF}$, and trace levels of radionuclides and metals. Unless supplemental plenum heating is added, or the CCIM is operated at a significantly higher temperature, or without a cold cap, the offgas temperature leaving the melter will probably be between 100 and $200^{\circ} \mathrm{C}$. Operation at the higher temperatures attainable with the CCIM, could dissociate sulfate salts in the waste, preventing the formation of a separate molten salt phase. This would eliminate one potential problem, but the offgas system would then have to be treated for an additional acid gas as well as likely greater amounts of other species, particularly cesium. Design of the system will be a compromise between feed rate, which is probably the primary operational objective, and offgas treatment, which is probably the greatest operational challenge. Preliminary testing with the CCIMs at $1150-1200^{\circ} \mathrm{C}$ in Russia and France should determine if there are significant differences from data taken with JHMs. Additional development will be required to determine the potential ramifications of operating at higher temperatures.

In general, sufficient nitric acid based scrubbing to condense acid gases and filtration to remove entrained particles will be necessary prior to final carbon-based sorption for mercury and residual NOx/SOx abatement. This can be carried out in 304L stainless steel at nominal conditions that are well documented based on JHM experience.

If process development leads to operation at higher temperatures, the offgas system may have to be augmented to prevent deposition of condensing alkali metals (film-cooler) and designed to withstand the corrosive effects of greater halogen concentrations. Depending on the effectiveness of the reducing agent and how completely it is consumed, the offgas system may have to accommodate greater levels of NOx (reduction) as well as $\mathrm{CO}$ (oxidation). This will have to be determined during flowsheet development at the pilot scale. Pilot scale testing will also provide insight into how effective recycle of offgas solids can be. This will help to define secondary wastes, their quantities, and disposition pathway.

Mercury capture remains an open issue for either type of melter. Speciation of the mercury released, and optimizing removal will require further development.

Recycle of offgas treatment scrub solution residuals must also be quantified. Depending on the process temperature selected, recycle may or may not be a reasonable option.

\subsection{Process Measurement and Controls}

There are a number of design issues associated with controls and instrumentation. For melter temperature control it essential that melt temperature at one or more locations within the melt be measured directly or indirectly. Surface temperature may not be suitable due to uncontrolled variations in emissivity. Sensors must be able to indicate melt temperature and be compatible with the induction heating process. It may be possible to gate the heating such that it can be momentarily interrupted during temperature measurements with a standard thermocouple, but this can not be done during inductive heating. It may also be possible to configure sensors that are insensitive to the induced field. There are various process variables that can be adjusted to 
maintain a desired temperature. Variations in feed rate, pour rate, and melter power all affect temperature and may be used as controlled variables. With sufficient pilot-scale experience it may be possible to infer melt temperature satisfactorily from melter power, and cooling water heat transfer.

In addition, liquid level within the melter must be maintained within certain limits and likely must be known to control temperature accurately. Level may be determined optically by observing a step change in thermal emission, hydraulically using dip tubes or equivalent device, acoustically using ultrasonics, or electrically using a conductive liquid level detector. Note, however that the melt is highly corrosive to some materials and non-contact measurements eliminate this problem. Level control during feeding and pouring is essential, particularly during the relatively rapid changes if pouring is done intermittently.

Dynamic response of the melter system to transients such as addition of feedstock or removal of melt present challenges to feedback control system design. Embedded in the melter operational response are phase changes, and such things as variations in specific heat, electrical resistivity, and magnetic permeability with temperature. These all present design challenges during control algorithm development, and must be characterized and understood during system process modeling.

\subsection{Safety Design}

There are a number of safety issues associated with CCIM operation. The presence of hot corrosive material, combustible gasses, and substantial electrical potential fields all represent potential threats to human health and safety. These threats can be mitigated by appropriate system-level design measures including a safety oriented process configuration, and active and passive engineered safety systems.

\subsubsection{Electrical}

The RF generator unit and its associated power control system unit have electrical potentials of hundreds or thousands of volts. These are both direct and alternating current RF. In addition, there will be three-phase power line potential in the power supply unit. Standard procedure to deal with these potentials is encasement of all electrical systems with conductive personnel shielding or barriers. In addition there are typically active interlocks that automatically deenergize systems when protective shielding or covers are removed. The Khlopin system is not operated with covers removed, and the assembled RF generator, power control unit, and CCIM are not operated unless all access doors are bolted closed and shielding is clamped in place. There are no exposed "hot" wires or bare cable connectors. Their system has no interlocks and controls are administrative only.

\subsubsection{Radiated Emissions}

Radiated emissions are of concern due to the high radio frequency (RF) fields generated by many tens of kilowatts of energy being generated and transferred to the melter crucible. In the United States whole body human radiated susceptibility is governed by ANSI/IEEE Standard C95.1 1991 (reaff. 1997), Standard for Safety Levels with Respect to Human Exposure to Radio Frequency Electromagnetic Fields, $3 \mathrm{KHz}$ to $300 \mathrm{gHz}$. There are two ways to reduce RF field levels to compliant values: distance and shielding. Remote operation, if practical, is a logical means to provide distance between the CCIM system and the operators, and is certainly one way to meet the intent of this standard. A conductive metal cage, called a Faraday shield, can also be design 
to reduce field levels to acceptable values, and may prove more practical in situations where space is more limited. In Russia there is a radiated susceptibility human exposure standard similar to IEEE C95.1, and laboratories working with this type of equipment are required by a regulatory agency to have an RF field survey done. In addition, the Khlopin system has a metal shielding enclosing the RF generator and induction coil.

Engineered safety devices must be engineered to operate within the strong RF fields present during CCIM operation. This will likely require separate shielding or selection of instruments and actuators that are insensitive to RF.

\subsubsection{Cooling (Loss of Coolant)}

Copper is used for the experimental cold-crucible at the KRI because it is electrically more transparent to the induction coil (lower dielectric permeability) than a stainless steel crucible. However, this construction also makes failure due to a loss of cooling more immediate, because of the lower melting point of copper. For this reason, as well as chemical corrosion resistance, a production unit would be fabricated from stainless steel. A system would also be equipped with a pressurized backup cooling system, interlocked with the power supply to de-energize the system at some preset cooling water outlet temperature and flow rate.

\subsubsection{Corrosives}

The SBW feed and the offgas scrub are both nitric acid based, requiring 304L/316 SS construction, including the feed, melter, and offgas systems. Cooling of the crucible will probably be designed on the back side of the crucible wall to provide a significant metallic layer between corrosive liquids/gases and cooling water flow channels. Electrical components not in contact with the feed (induction coil) will be designed to maximize their electrical performance.

\subsubsection{Over-Pressurization}

Designed with an induction-heated bottom drain, a CCIM should not be affected by pressure excursions. The offgas system design must accommodate pressure fluctuations typical to coldcap operation with a JHM, scaled to the potential feed rates attainable with the CCIM.

\subsubsection{Drain failure}

The drain system could fail by uncontrolled heating, insufficient or loss of cooling, or corrosion. Plugging is not believed to be a likely failure mode as long as the induction coil is in operation. Catastrophic failure causing the melter inventory to drain, though unlikely, must be designed for. Several JHMs have failed due to unexpected circumstances, leading to significant loss of supporting systems. One critical advantage of the CCIM is its small inventory in process at any given time. This allows a basin to be designed around the glass receiving canisters that could accommodate the entire melter inventory. Such a containment system would protect the cell and ancillary systems from damages due to a glass spill.

\subsubsection{Combustible Gases}

Under the current design concept, a reducing agent, such as sugar, would be added to the feed to convert most of the nitrate into nitrogen. At this time, it is difficult to predict exactly how effective this will be, or how completely the sugar will be oxidized to carbon dioxide. Thus, 
instruments will be necessary to monitor combustible gases to preclude an explosive mixture in the offgas system.

\section{PROCESS DESIGN FOR DEVELOPMENT AND TESTING}

\subsection{General Issues}

The CCIM technology is based on electromagnetic phenomena that must be understood to design and control a process. This effort will require some testing and parameter measurement that is unique to the CCIM. However, once these unique features are adapted to the SBW application, the remaining issues are common to development of any thermal process for treating this type of waste.

A rough list of the outstanding issues are:

- Verification of optimal frequency and crucible conformation to maximize throughput and control (cylindrical, oval, rectangular, asymmetrical, etc.)

- Optimal frit chemistry to process SBW exploiting the greater corrosive and temperature tolerance of the CCIM design (Vienna/Peeler)

- Verification of new glass chemistry in CCIM, define glass electrical and physical parameters versus temperature

- Electromagnetic/thermal/fluids modeling to simplify testing and develop a control strategy. (Foreign collaboration)

- Electromagnetic field affects on instrumentation and design of personnel areas

- Melter physical size and access requirements

- Optimal operating temperature balancing operating flexibility (waste loading and throughput) versus complexity (higher volatility and carryover)

- Techniques to maximize throughput, convective versus mechanical mixing, moisture content, etc.

- Melter throughput as a function of feed concentration/chemistry

- Define safety measures, including emergency procedures, loss of coolant or coolant leaks to the crucible, phase separation induced instability, and containment of EMF

- Techniques to ensure glass quality/homogeneity - batch versus continuous operation, premixing frit and waste, on-line instrumentation, etc.

- Offgas flowrate, composition and particle loading

- Evaluate best approach to dissolution versus volatilization of waste constituents (thermally labile salts e.g. SO4, NO3, halides, alkali, and alkaline earth elements) 
- Evaluation of operable melt chemistry envelope to preclude foaming, phase separation, and RedOx conditions

- Glass melt level control

- Glass pouring mechanism, initiation, termination

- Utility requirements - quantify power and cooling requirements/efficiencies

- Best method for startup: reusable versus consumable starter

- Best method for shutdown: draining/cooling versus minimum melt level in hot standby

- Identification of maintenance items, expected need for replacements and installed spares.

This list is not comprehensive, but provides a good basis for the work scope left to perform before any alternative melter system can be designed.

Ideally, a pilot plant designed for developing the CCIM technology would allow not only evaluation of the core technology, but the characteristics of its response to process upsets and requirements for safety systems. The system should accommodate several different crucible configurations, allowing developers the opportunity to evaluate novel crucible geometries versus the baseline right-cylinder. Crucible cross section, melt mixing, and glass flow path, i.e. underflow, overflow, bottom drain, all warrant evaluation. Similarly, a pilot-plant power supply should be variable frequency to evaluate performance for specific glass chemistries at different frequency of applied field. Many potential designs may be eliminated through analytical modeling of energy deposition and thermal profile. However, it is expected that at least a few potential designs will warrant testing to determine if the processing capacity, melt homogeneity, pouring, level control, and/or process control can be improved. The system should have the capability to overfeed to determine how the system recovers from an excursion as well as the maximum maintainable productivity. Similarly the offgas system should be oversized to accommodate the gases generated during excursion testing without compromising containment.

\subsection{Controls}

A pilot or experimental cold crucible induction melter system has at least two fundamental control requirements: melt temperature and level control. Under steady state conditions, melt temperature is most sensitive the energy being induced from the induction coil. Thus a logical control design will measure or infer melt temperature, compare this value to a desired value, and vary input power to correct any differences. There are technical issues that make this problem nontrivial. Energy absorption and heat distribution within the melt are functions of electrical resistivity, electromagnetic permeability, thermal conductivity, specific heat, viscosity, and other things. Some or all of these, turn, are affected by temperature, phase and phase changes, melt chemistry, and electrical frequency. In addition, normal operation is not really steady state. Batch input feed and melt pour (removal) are transient perturbations that must be accommodated. There also may be somewhat slower changes in crucible cooling heat removal. These are all expressed as time varying quantities that requires the control system to be capable of dynamic response.

Part of the control scheme development will be dedicated to characterizing the glass melt electrical properties versus temperature and frequency. Melt resistivity, thermal conductivity, and 
specific heat are all important to modeling and control. Sensitivity of these variables to chemistry changes, particularly waste loading should also be examined.

Melter level control and monitoring during feeding and pouring will be key pilot plant capabilities. Precise monitoring of melt level will provide direct feedback on processing and pouring rates, as well as a means to quantify pouring control. Design of a sufficiently responsive control system for melter pouring is critical to safe, routine operation. Pouring will likely be done via a remotely operated freeze valve. Melter level detection can be done acoustically, electrically, optically, or possibly using some other technology. Control will likely be binary with continuous safety monitoring, and with an active link to the control system.

\subsection{Feed System}

An experimental system should have the capability to feed finely divided solids, liquids and mixtures (slurry to paste) in essentially any proportion. The poorly defined feed rheology may require a peristaltic pump, an Archemedes screw, and loss-in-weight dry feed bins. The SBW surrogate contains about $220 \mathrm{~g} / 1$ dissolved solids, which are supplemented by sugar and either glass forming chemical additives or powdered glass frit. This can easily result in a feed that is over $50 \mathrm{wt} \%$ suspended and dissolved solids. The liquid feed system must be constantly agitated and circulating, with a side stream feeding the melter. Depending on the location, the feed and makeup system will probably require heating and may require cooling. Control of feed mixing in the proper proportions will be essential to melter control and reproduceable results.

\subsection{Offgas System}

The offgas system will be fairly standard, but should be designed to facilitate characterization. Nitric acid based scrubbing/quenching, deentrainment of droplets, superheating and HEPA grade filtration will form the baseline system similar to the offgas system for the calcination at the INEEL. Capabilities for testing with mercury and NOx, SOx abatement will be required.

\subsection{Cooling System}

The cooling system will probably have to be recirculating relatively high-purity water, with a secondary air or water-cooled heat rejection system. The relatively high-purity is needed to reduce conductivity in the crucible as well as reducing the potential for internal corrosion or deposit formation. The system will have to recirculate to be economical.

\subsection{Scaling Issues}

Melter productivity and offgas generation are key to process scaleup. Thus, CCIM conformation, aspect ratio, and offgas flow velocities are significant design parameters. Conformation and aspect ratio are expected to control coupling with the induction coil and melt rate. Gas movement over the melt, de-entrainment space over the melt surface, and gas velocity over the melt are all believed to be critical to solids entrainment and cooling of offgas semivolatiles. 


\section{CURRENT TESTING PROGRAM AND PRELIMINARY RESULTS}

The current test program at the Khlopin Radium Institute is limited to a preliminary evaluation of the Russian CCIM technology. The intent of the LDRD is to provide enough factual information to the HLW Program, to have this technology considered as an option to the baseline joule-heated melter. The LDRD is also exploring the potential for an iron phosphate glass alternative to the baseline borosilicate composition for immobilizing SBW. An iron phosphate glass matrix has been developed at the University of Missouri, Rolla, and samples have been provided to the INEEL HLW Program for verification analyses, which are to be completed in FY-02. If costeffective, qualification of a non-borosilicate host glass will be pursued.

Results to date for the LDRD include:

- Three experimental melts were performed with Run 78 calcine chemistry and the borosilicate baseline composition at waste loadings of 33, 38 and 43 mass $\%$ of simulated INEEL waste oxides in the final product.

- All three glass compositions display a considerable increase in electrical conductivity as temperature is increased above the melting point, requiring the operator to avoid overheating the melt.

- $\quad$ The product glasses were $99+\%$ amorphous.

- $\quad$ PCT results improved with higher waste loading. Preliminary PCT results are:

\begin{tabular}{|c|c|c|c|c|}
\hline \multicolumn{5}{|c|}{ Nominal PCT Results Averaged over Melt Depth $\left(\mathrm{g} / \mathrm{m}^{2}\right)$} \\
\hline $\begin{array}{c}\text { Run 78 Calcine } \\
\text { Waste Loading }\end{array}$ & $\mathrm{r}_{\mathrm{B}}$ & $\mathrm{r}_{\mathrm{Si}}$ & $\mathrm{r}_{\mathrm{Li}}$ & $\mathrm{r}_{\mathrm{Na}}$ \\
\hline $33 \mathrm{wt} \%$ & 0.662 & 0.187 & 0.835 & 1.020 \\
\hline $38 \mathrm{wt} \%$ & 0.623 & 0.162 & 0.729 & 0.943 \\
\hline $43 \mathrm{wt} \%$ & 0.252 & 0.094 & 0.491 & 0.620 \\
\hline
\end{tabular}

- Three experimental melts were also performed with SBW chemistry and the borosilicate baseline composition at waste loadings of 25,30 , and $35 \mathrm{wt} \%$ of simulated INEEL waste oxides in the final product.

- Melting time was reduced at higher waste loading due to the fluxing properties (higher conductivity) of the SBW surrogate. Preliminary PCT results are:

\begin{tabular}{|c|c|c|c|c|}
\hline \multicolumn{5}{|c|}{ Nominal PCT Results Averaged over Melt Depth $\left(\mathrm{g} / \mathrm{m}^{2}\right)$} \\
\hline $\begin{array}{c}\text { SBW Chemistry } \\
\text { Waste Loading }\end{array}$ & $\mathrm{r}_{\mathrm{B}}$ & $\mathrm{r}_{\mathrm{Si}}$ & $\mathrm{r}_{\mathrm{Li}}$ & $\mathrm{r}_{\mathrm{Na}}$ \\
\hline $25 \mathrm{wt} \%$ & 0.376 & 0.276 & 0.959 & 0.592 \\
\hline $30 \mathrm{wt} \%$ & 0.766 & 0.296 & 0.892 & 1.083 \\
\hline $35 \mathrm{wt} \%$ & 0.907 & 0.395 & 0.994 & 1.521 \\
\hline
\end{tabular}


- Iron phosphate glasses were also evaluated at the University of Missouri, Rolla for immobilizing SBW. The recommended iron phosphate glass (IPG) matrix melts at $1000 \mathrm{oC}$ and immobilizes $40 \mathrm{wt} \% \mathrm{SBW}$.

- Glass liquidus temperature for the IPG is $740 \mathrm{oC}$, and the lower viscosity $(0.55$ Poise at $1000 \mathrm{oC}$ ), melting time is reduced to 2 hours to produce a homogeneous melt under laboratory conditions.

- The PCT protocol was designed specifically for borosilicate glass. Thus, results with the iron phosphate matrix are not directly comparable. The results for aluminum and phosphorous are offered in the table below in the position of boron and silicon. Iron and silicon would be the comparable primary cation and anion in the host matrix, but the iron release rates are essentially at detection levels. Results for potassium and sodium are shown in place of lithium and sodium, the primary fluxing cations. Preliminary PCT results are:

\begin{tabular}{|c|c|c|c|c|}
\hline \multicolumn{5}{|c|}{ Nominal PCT Results Averaged over Melt Depth $\left(\mathrm{g} / \mathrm{m}^{2}\right)$} \\
\hline $\begin{array}{c}\text { SBW Chemistry } \\
\text { Waste Loading }\end{array}$ & $\mathrm{r}_{\mathrm{Al}}$ & $\mathrm{r}_{\mathrm{P}}$ & $\mathrm{r}_{\mathrm{K}}$ & $\mathrm{r}_{\mathrm{Na}}$ \\
\hline $40 \mathrm{wt} \%$ & 0.06 & 0.13 & 0.16 & 0.32 \\
\hline $48 \mathrm{wt} \%$ & 0.26 & 3.72 & 5.55 & 6.03 \\
\hline
\end{tabular}

- Waste loading may be somewhat misleading for the iron phosphate, because the waste loading in the baseline borosilicate composition is limited to $20 \mathrm{wt} \%$ due to sulfate solubility, not PCT results. Thus, additional evaluation will be necessary in FY-02.

- One CCIM experiment has been performed with the IPG glass and the electrical properties are quite favorable to this type of processing. Again, this work will continue in FY-02. 
This page intentionally left blank. 


\section{APPENDIX A: \\ SUMMARY OF TRIP TO VISIT RADON AND KRI}

\section{Introduction}

During the first and second weeks of March, 2001, Dirk Gombert and John Richardson visited with representatives of the Moscow Scientific and Industrial Association in Moscow, Russia, and the V. G. Khlopin Radium Institute (KRI) in St. Petersburg. The purpose of these visits was to discuss current operations and applications of their cold crucible induction-heated melters (CCIM's), and to initiate collaborative work with KRI. We also visited the KRI laboratories and witnessed a test melt of waste simulant. This report summarizes the discussion and observations associated with CCIM energy generation and deposition, physical configuration, and process control, as well as general information associated with application and operation of the melters in Russia.

\section{Moscow Scientific and Industrial Association (RADON)}

\section{The Current RADON System}

RADON representatives included Dr. Sergey Stefanovsky, Dr. Victor Vlasov, and an electrical engineering graduate student. We initially discussed a melter system they currently have operating at a facility approximately $90 \mathrm{~km}$. outside Moscow producing borosilicate glass containing about $33 \mathrm{wt} \%$ oxides from a sodium nitrate based low level waste. The waste glass contains $30-35 \mathrm{wt} \%$ from waste oxides (primarily sodium with some calcium nitrate, and a few percent of sodium sulfate and chloride) and $65-70 \mathrm{wt} \%$ glass additives (about 2/3 silica, with equal amounts of borate and alumina) and has a viscosity of about 3-5 Pa-s. This is very similar to the sodium bearing wastes at the INEEL. The glass contains small sulfate inclusions that reportedly do not impact glass leach performance or melter operation. Glass is poured into 10 liter containers, filled with two batch pours.

The system consists of three parallel production lines each with its own melter, with two running at any one time producing a total of up to $75 \mathrm{~kg}$ glass $/ \mathrm{hr}$. The melters operate at a nominal temperature of $1150-1170{ }^{\circ} \mathrm{C}$. Power is 80 kilowatts per melter. The melter cross sections are approximately $20-50 \mathrm{~cm}$ ovals, about $50 \mathrm{~cm}$ deep. The generator system is vacuum tube based operating as a class $\mathrm{C}$ oscillator or amplifier at a frequency of $1.76 \mathrm{MHz}$. The induction coil is copper and the cooled crucible assembly is fabricated from stainless steel. The cold skull produced inside the crucible is approximately $1 \mathrm{~mm}$ thick.

The 20-25 wt $\%$ water nitrate-salt paste is fed with a peristaltic pump to maintain a cold-cap on the melt, so offgas temperature is only about $100^{\circ} \mathrm{C}$ and cesium losses are less than $3 \%$. Entrained particles are caught on a metal mesh filer (10s of microns), then the gas is HEPA filtered, scrubbed for NOx and residual NOx is catalytically reduced using vanadium on an alumina support. The offgas system design is patented in various countries, including the United States.

\section{Design Criteria}

We talked a bit about design criteria and melter feedstock. RADON uses a $10^{-6} \mathrm{grams} / \mathrm{cm}^{2} /$ day leach rate limit for cesium as a primary requirement. Their objective is to produce glass that 
exhibits a compressive strength of $200 \mathrm{~kg} / \mathrm{cm}^{2}(20 \mathrm{mP})$. Their feedstock is supplied as a $20-25 \%$ slurry using a peristaltic pump.

\section{Oval Melter Design}

Dr. Stefanovsky and Dr. Vlasov both discussed the melter design itself. The Russians have modeled energy transfer and have found they can obtain electrical energy transfer efficiencies of $80 \%$ by meeting the following criteria:

$$
\begin{gathered}
\mathrm{m}=\phi_{\mathrm{c}} /\left\{(\sqrt{ } 2) \Delta_{\mathrm{m}\}} \text { where } 3<\mathrm{m}<5\right. \\
\phi_{\mathrm{c}} \equiv \text { crucible diameter } \\
\Delta_{\mathrm{m}} \equiv \text { depth of penetration }
\end{gathered}
$$

For their current glass formulation and their current $1.76 \mathrm{MHz}$ operating frequency, penetration depth is approximately $5-7 \mathrm{~cm}$. Thus a large crucible would fall outside the optimum range under these conditions. One way to get around this is to design a oval shaped crucible. This will minimize the temperature variation across the plane of the melt for two reasons: the average distance from the walls is less such that the penetration depth encompasses all of the volume, and there is more surface area bounding the inner $30 \%$ of the melt volume, increasing efficiency of heat transfer to the core. The RADON melters themselves are $56 \mathrm{~cm}$ by $20 \mathrm{~cm}$ oval shaped in cross section, and are approximately $50 \mathrm{~cm}$ high.

\section{System Configuration}

Victor Vlasov outlined the overall power and control system configuration. Figure 1 is a copy of his system configuration drawing.

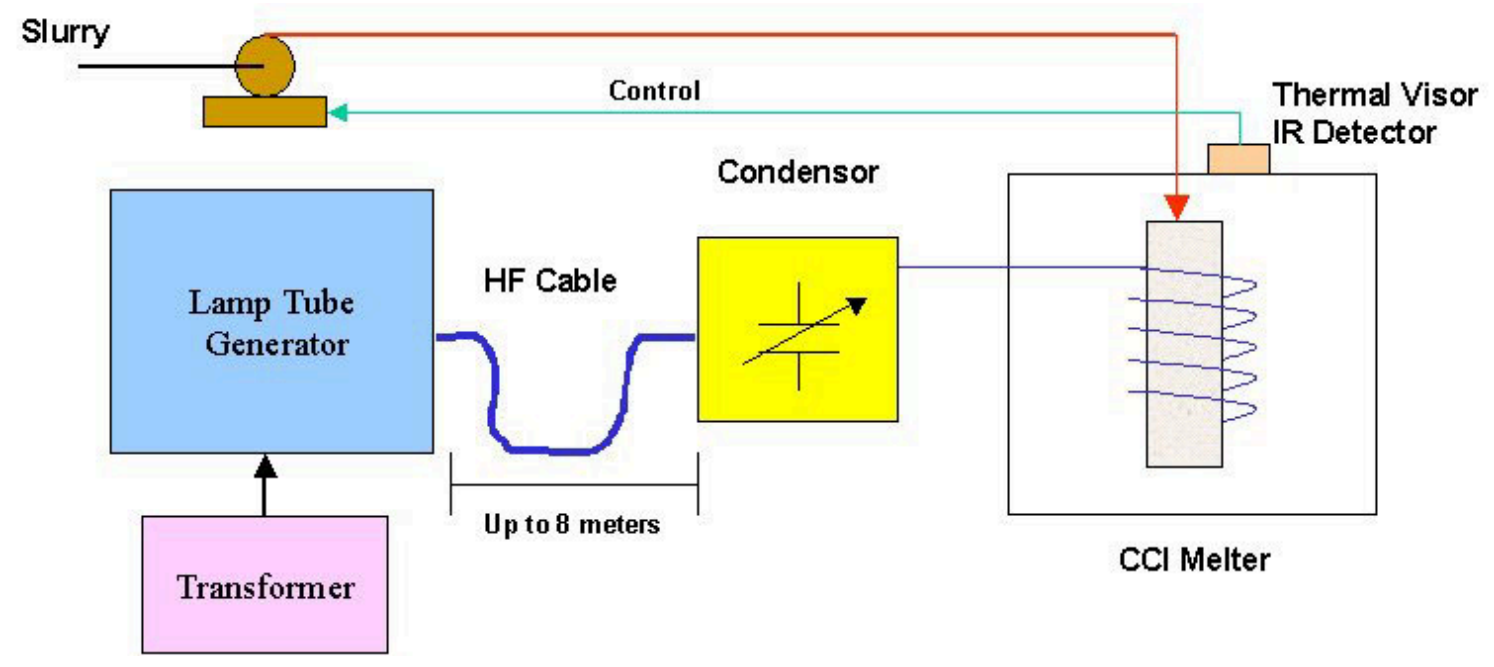

Figure 1. RADON Power and Controls System Configuration

Dr. Vlasov outlined five primary elements of the RADON production system. The transformer is a multiphase rectification system that provides power to the subsequent stages. Primary power is 
generated by a large vacuum tube Class $\mathrm{C}$ amplifier that they call a lamp tube generator. The $\mathrm{RF}$ energy is transferred to the vicinity of the melter via a coaxial cable. Tuning of the inductor is done remotely with a motorized variable capacitor across the melter inductor coil. This tuning is done manually by the operators. The melter itself is a cold crucible type as described earlier. Slurry is provided to the melter with a slurry pump. Other components including the melter output and offgas control system are not shown because they do not interface directly with the power and controls functions.

\section{Energy Generation and System Control}

The RADON melters control power input to the to the final class $\mathrm{C}$ amplifier. They refer to this as a lamp tube generator. Note that the power transferred to the melt may vary with changes in resistivity. An automatic feet system is controlled by a melt surface temperature measurement. This is taken with a ThermalVisor infrared emission sensor. Melt temperature is inferred from surface temperature. This relationship is based on both modeling and experience measuring actual melt temperature in past tests. The control scheme is bi-state. When the temperature reaches a set-point level, a fixed amount of slurry is metered into the melt. The system then waits until the temperature returns to the set-point and then meters an additional fixed amount of slurry. Cycle time is on the order of minutes. They noted they have feedback to the amplifier, but seemed unsure if this is part of an interactive feedback control scheme. There are two possibilities. One is that they have closed loop control to maintain constant output from the amplifier by measuring inductor voltage and current. This is how the KRI bench top melter (described later) is designed. The second is that they use this as part of an engineered safety system to remove power when certain criteria are met.

\section{Frequencies and Shielding}

There is a relationship between resistivity, magnetic permeability, and excitation frequency that determine penetration depth, and hence melter dimensions. These factors also affect the efficiency of energy transfer to the melt. Resistivity and magnetic permeability are functions of the waste makeup and temperature. Frequency should be an independent variable, and in fact Dr. Stefanovsky and Dr. Vlasov worked at various frequencies with a shielding bench top unit melting high level waste. The Russian government imposes radiated emissions limits on such devices. Adequately shielding larger melters has proven impractical from a cost standpoint, so RADON has been restricted to operating within reserved frequency bands. As noted earlier, 1.76 $\mathrm{MHz}$ was chosen for their current production system. The French have been looking at lower frequencies as a means of obtaining a more uniform temperature across the plane of the melt. As noted above, the Russians have addressed this problem by utilizing an oval shaped planar cross section. A round cross-section can be used to increase the temperature gradient, thereby increasing convective mixing, or an oval can be used for greater electrical efficiency. These effects are obviously affected by melt resistivity and viscosity. A mathematical model to integrate the electrical, thermal, and fluid properties of the CCIM and glass would be an essential design tool.

\section{Melt Initiation}

Resistivity of the unmelted waste material is too high to facilitate inductive energy transfer directly, thus melting must be initiated somehow. There are three ways to accomplish this. The most common technique, which RADON is using now, is to insert a rod of conducting material composed of silicon-carbide or graphite prior to initiating the melt. A second technique is to insert a slotted titanium ring. Upon application of the radio frequency field, an arc occurs across 
one or more of the slots thus initiating the melt. A third technique is to apply a magnetite paste on the surface of the waste prior to melting. This paste will heat rapidly when the melter is started, and like the rod and slotted ring, melt waste in the immediate vicinity to initiate the melting process.

\section{Continuous Batch Operation}

The RADON production melters are operating in the continuous batch mode, that is feed is added incrementally, and fixed volumes of melt are removed periodically. Feed to the melter is $50 \mathrm{~kg}$. per hour, which results in $30 \mathrm{~kg}$. per hour of new melt. Total depth of melt and feed in melter is $30 \mathrm{~cm}$. Depth changes approximately $10 \mathrm{~cm}$. when melted waste is removed. The 10-liter holding containers for the melted waste are filled in two separate pours from the melter. Pouring is done through a side tap, but a bottom drain would be used if the waste contained significant amounts of noble metals.

\section{Other US National Lab Work}

Savannah River initiated funding to design a $500 \mathrm{~kg} / \mathrm{hr}$ unit to process iron phosphate glass. This funding was either terminated or not fully transferred. RADON also talked about another melter design associated with SRS (or their funding) which was a 100kg/hour 10 megawatt system to produce boro-silicate glass as a replacement for the DWPF melter. Dr. Stefanovsky also noted also that PNL folks visited MINATOM to discuss CCIM technology in Russia.

\section{Large vs. Small Melters}

Their opinion is that smaller melters, in general, represent a better alternative than larger melters because they have a larger ratio of surface area to volume, can use higher frequencies which are more efficiently, and thus for a given power level provide a larger specific productivity (approx. 8 kg./ decimeter).

\section{Continuous Process Melter}

Dr. Vlasov spoke at length about continuous process high silica glass melter design. In contrast to the current continuous batch melter where the crucible is periodically "filled" and "emptied", the continuous process melter is fed with an uninterrupted flow of feedstock and provides a constant melt output to a receiving container. They have constructed such a melter. Below is a diagram illustrating the system. 


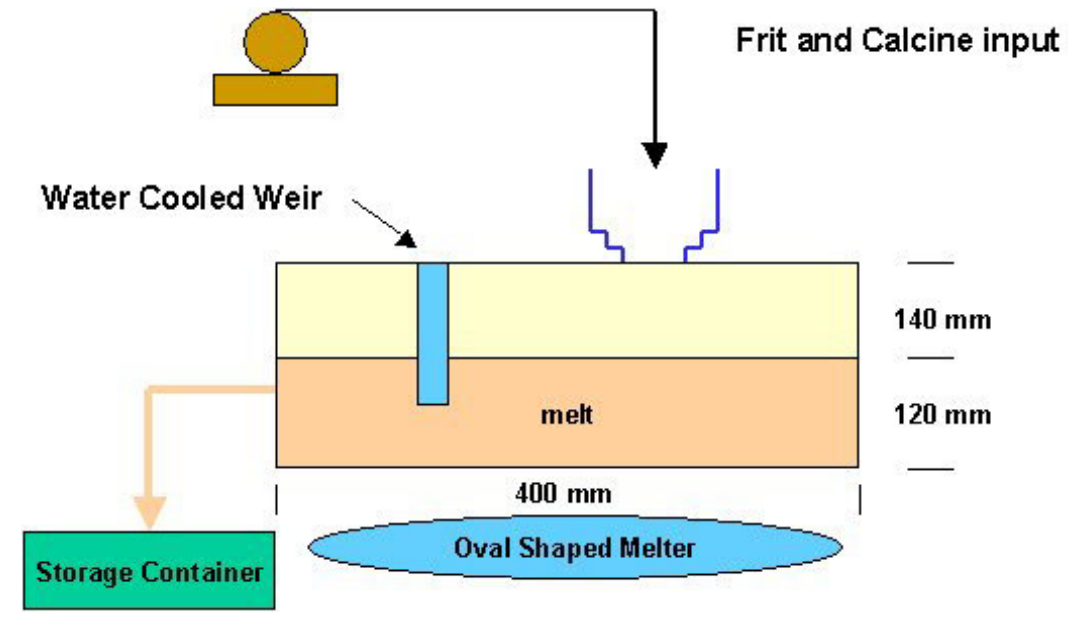

Figure 2. Continuous Melter System

As noted in Figure 2, this is an oval shaped melter configuration. It is rated at $23 \mathrm{~kg}$ per hour throughput with a ten-minute residence time. Normal operating temperatures are $1400-1700^{\circ} \mathrm{C}$, but has been operated as high as $2100^{\circ} \mathrm{C}$ for melting refractory materials. Frit and calcine are added separately by the feed system. A water-cooled weir isolates melt for output.

\section{Russian Industrial Applications}

The CCIM may appear novel to Americans working with radioactive wastes, but the technology is in common use in Russia where the materials to be melted are either very corrosive, or purity requirements are impacted by exposure to refractories. The CCIM is also chosen when the working temperature range precludes the use of refractory and electrode materials. Some of the applications discussed includes zircon crystals, alumina, garnet abrasives, and mineral wool. Operating temperatures up to $3000^{\circ} \mathrm{C}$ have been used.

\section{G. Khlopin Radium Institute}

The primary V. G. Khlopin Radium Institute (KRI) representative was Dr. Albert Alloy, who invited us to his laboratory to interview his staff and observe a melt run with his bench scale cold crucible melter. We also met with Professor Dr. Dmitry Lopukh of the St. Petersburg Elektrotechnical University (LETI). LETI designed the KRI melter and has also developed electrical/thermal models of cold crucible melters.

\section{Comments on the RADON System}

Initial discussions centered on the design and operational issues associated with the RADON melter system described above as applied to sodium waste and calcine waste. It was pointed out that using a moist waste feed consisting of $25 \%$ water results in low overall energy efficiency and that probably preprocessing (drying) should be considered. The offgas temperature of the RADON melters with a cold cap is close to $100{ }^{\circ} \mathrm{C}$, which lowers the volatility of cesium to only about $3 \%$. Conversely, with a dry waste feed the offgas temperature would be much warmer resulting in a greater volatility of $\mathrm{Cs}$, but higher process efficiency would result. Clearly, a trade- 
study would be of value here, and experiments should be conducted to maximize melting rate while maintaining volatility losses acceptably low.

\section{KRI Bench Top Melter Overview}

We had the opportunity to examine a bench-top cold crucible induction heated melter in Dr. Alloy's laboratory in some detail. Figure 3 is a photograph of their melter. The unit is a batch system operating at a power level up to $40 \mathrm{~kW}$, and cooled by an array of two-pass copper cooling channels. Electrically, the inductor is an RF unit driven by a direct coupled vacuum tube Hartley power oscillator. Control is manual and open loop with mechanical and electrical shielding provided by metal barriers. Data logging is done manually.

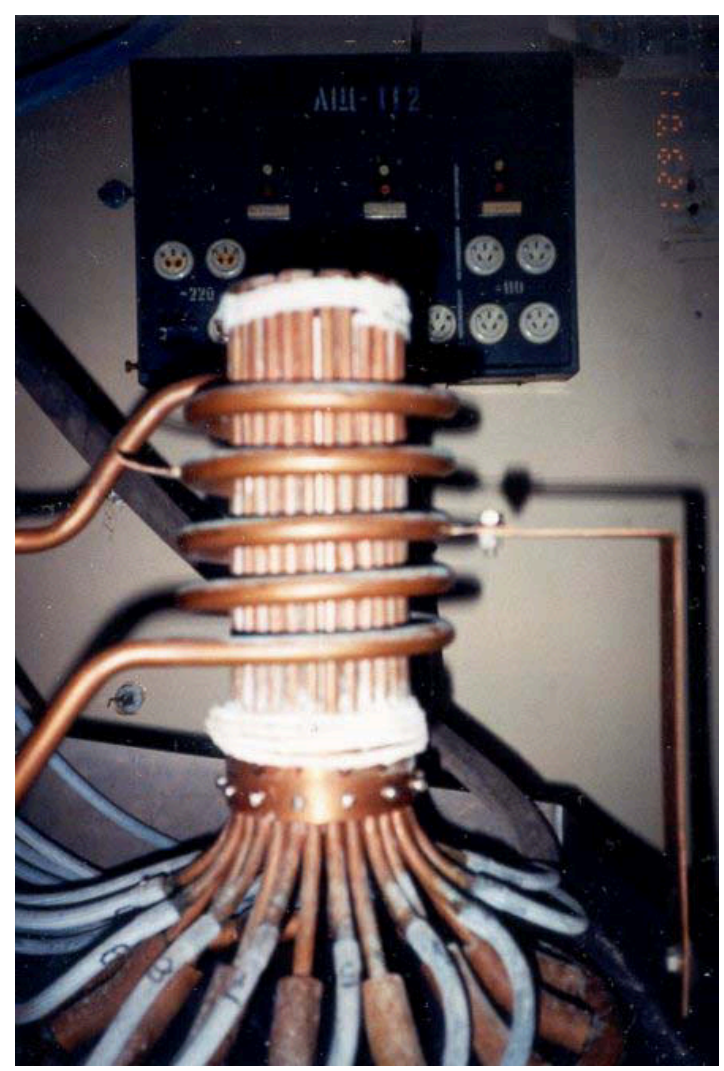

Figure 3. KRI Cold Crucible Induction Melter

The system design is very similar to that of the batch melter discussed with RADON earlier. Figure 4 is a system block diagram illustrating the primary components of the KRI bench-top melter system. Note that power generation and melter units are in separate shielded enclosures. Unlike the RADON system, they are short coupled. The generator is in a permanent enclosure. A temporary electrically shielded enclosure is place over the melter and adjacent to the lamp generator assembly prior to operation. 


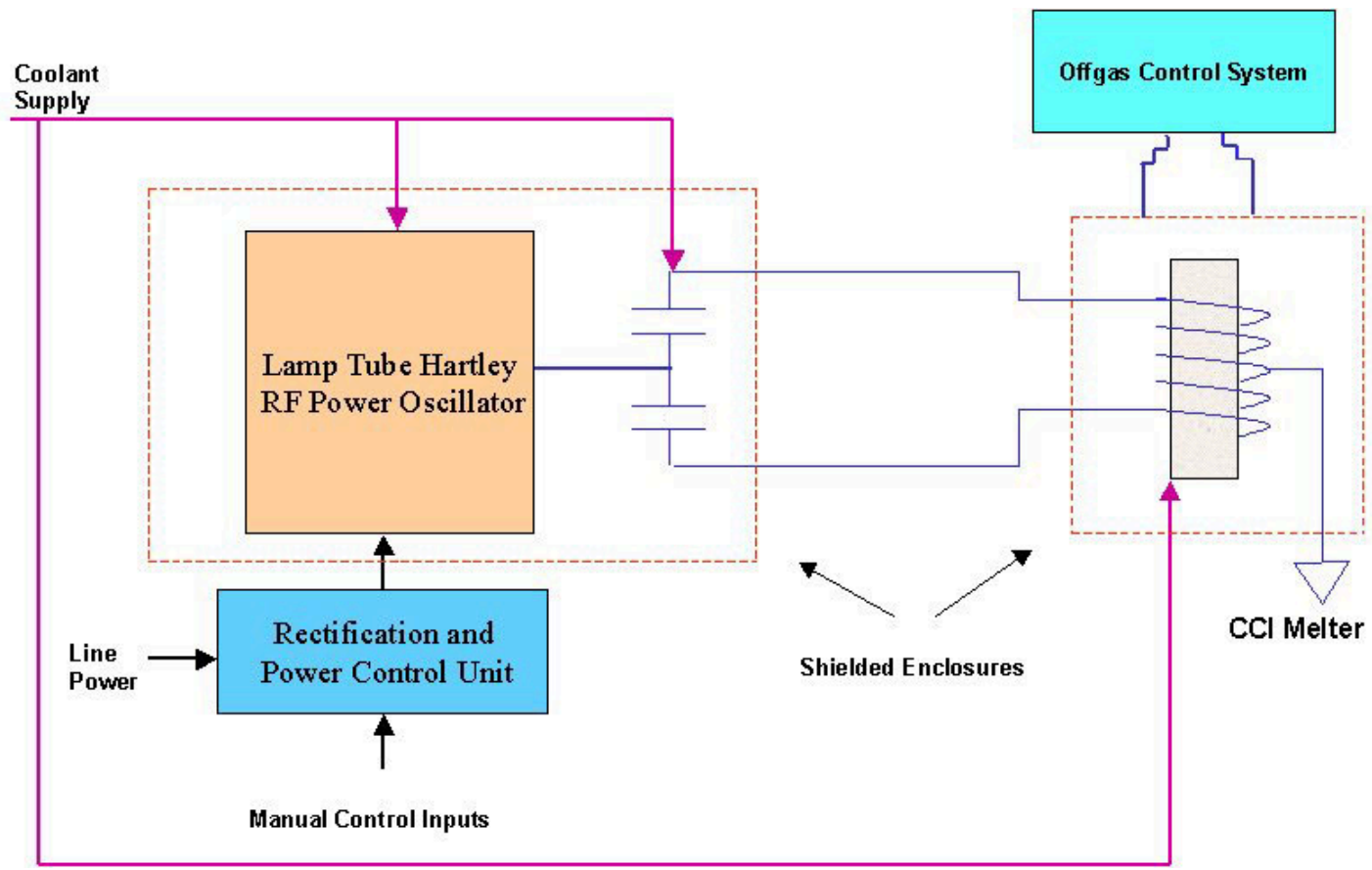

Figure 4. KRI System Layout

\section{Radio Frequency Generator}

Radio frequency (RF) power is generated at $1.76 \mathrm{MHz}$. During the melt sequence at the laboratory, input power to the CCIM inductor was measured at approximately 21 kilowatts. The $\mathrm{RF}$ generator is reportedly capable of input power levels of approximately 40 kilowatts. The unit is housed in a separate cabinet, as shown in Figure 5 below. In the photograph the access door is open so that the internal configuration can be observed.

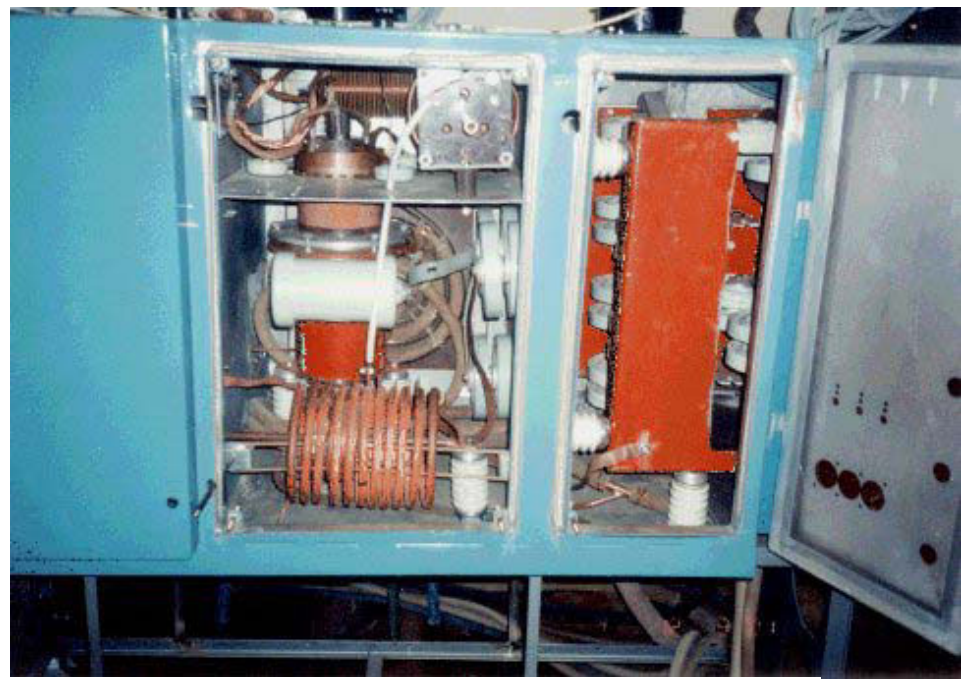

Figure 5. Side View of Lamp Tube RF Unit 
The RF unit is a single stage system consisting of a triode Hartley power oscillator. The triode is referred to as a lamp tube. Feedback is separately adjustable. See Appendix D, Schematic of Lamp Tube Generator and Inductor Coupling Network. The output is coupled to the CCIM inductor via a tap in the plate circuit. This serves to match the output impedance of the oscillator to the reflected impedance of the melter. The inductance of the plate circuit is also adjustable with a variable link for frequency tuning. Feedback is separately controlled via a variable inductor. Plate current and negative bias voltage are supplied by the rectification and power control system. Neither plate circuit nor feedback required tuning during the melter run we witnessed. Both are adjustable via mechanical linkages and external control knobs.

The plate dissipation energy of the power triode is removed via a water jacket cooling shroud. Similarly, coolant is supplied to the CCIM inductor, which consists of hollow copper tubing. See the description below of the induction melter component. Both lamp tube inductor receive coolant from the same manifold that provides cooling to the melter crucible itself.

Note the lamp tube in the left cavity as shown in Figure 5. The resonant tank circuit is horizontally mounted in front of the lamp tube. Note the coolant lines to the tube. The right cavity houses the capacitor bank necessary for tank circuit resonance, and the induction coil coupling capacitors.

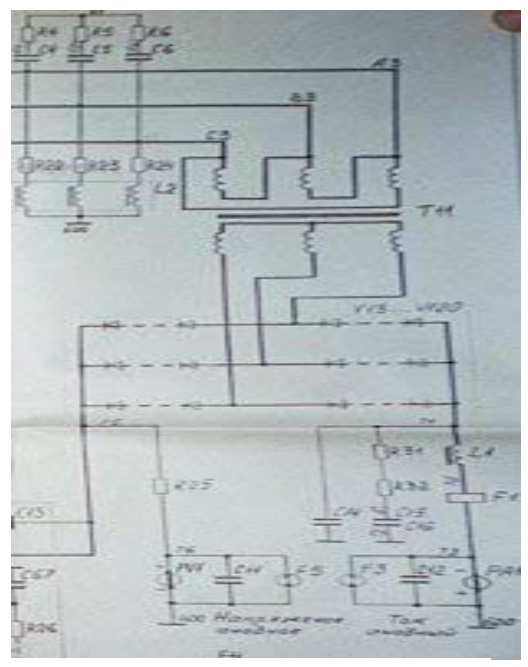

Figure 6. RF Generator Power Supply

\section{Rectification and Power Control System}

High voltage DC is generated by a three-phase bridge rectifier consisting of stacked semiconductor diodes as shown in Figure 6, a schematic of the rectification and monitoring system. Both plate voltage and current are monitored simultaneously. Voltage is measured directly, and current is measured via a resistive shunt.

Voltage is controlled using silicon controlled rectifiers (SCR's) wired in a bipolar configuration and performing switching to control the duty cycle of the input to the three phase power transformer shown to the right. Standard U. S. design would use an SCR-switched bridge rectifier, but operating voltage requirements for the bridge application SCR's is much higher than the that for the SCR's in their current design. Power oscillator plate and grid voltage are 
controlled and monitored, along with plate current from a separate control panel. Figure 7 is a photograph of this panel.

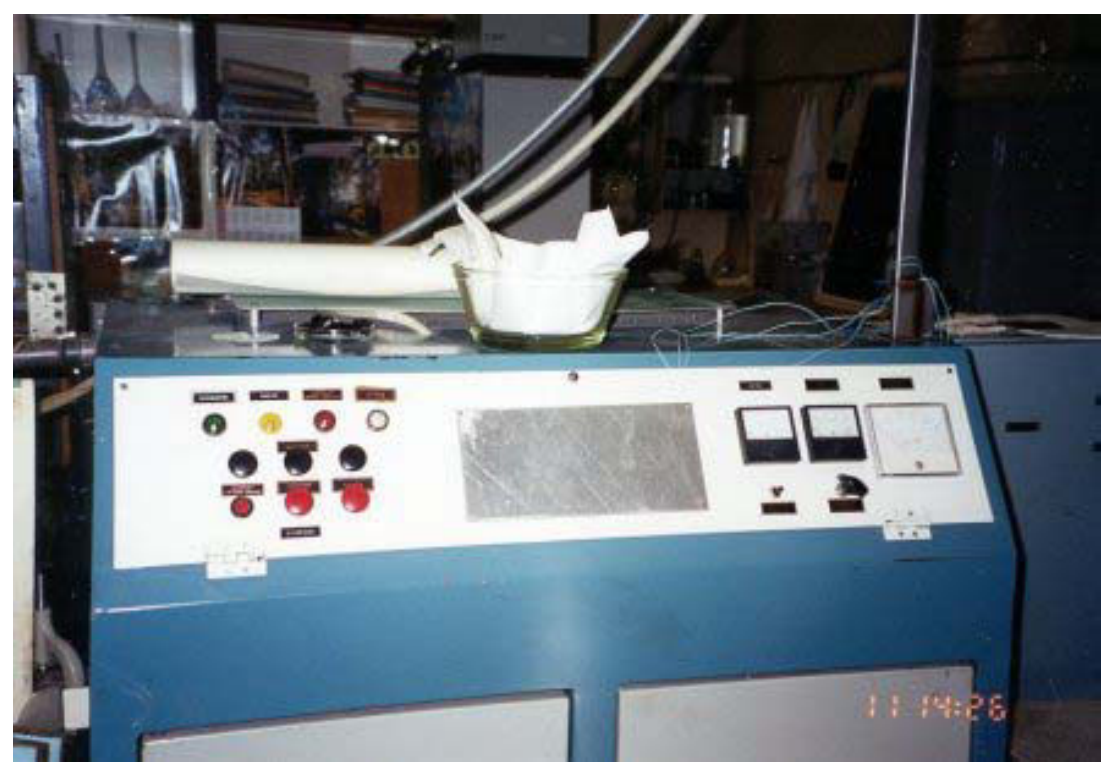

Figure 7. KRI Power Control Panel

\section{Induction Coil}

Power is transferred from the RF power generator to the inside volume of the crucible via an induction coil. The KRI CCIM induction coil consists of $4 \frac{1}{2}$ turns of copper tubing. The coil has an internal radius of $12.8 \mathrm{~cm}$. and a height of $17.6 \mathrm{~cm}$. The coil is hollow and is cooled with water supplied from the cooling manifold. Figure 8 is a close view of the induction coil before it is attached to the crucible assembly.

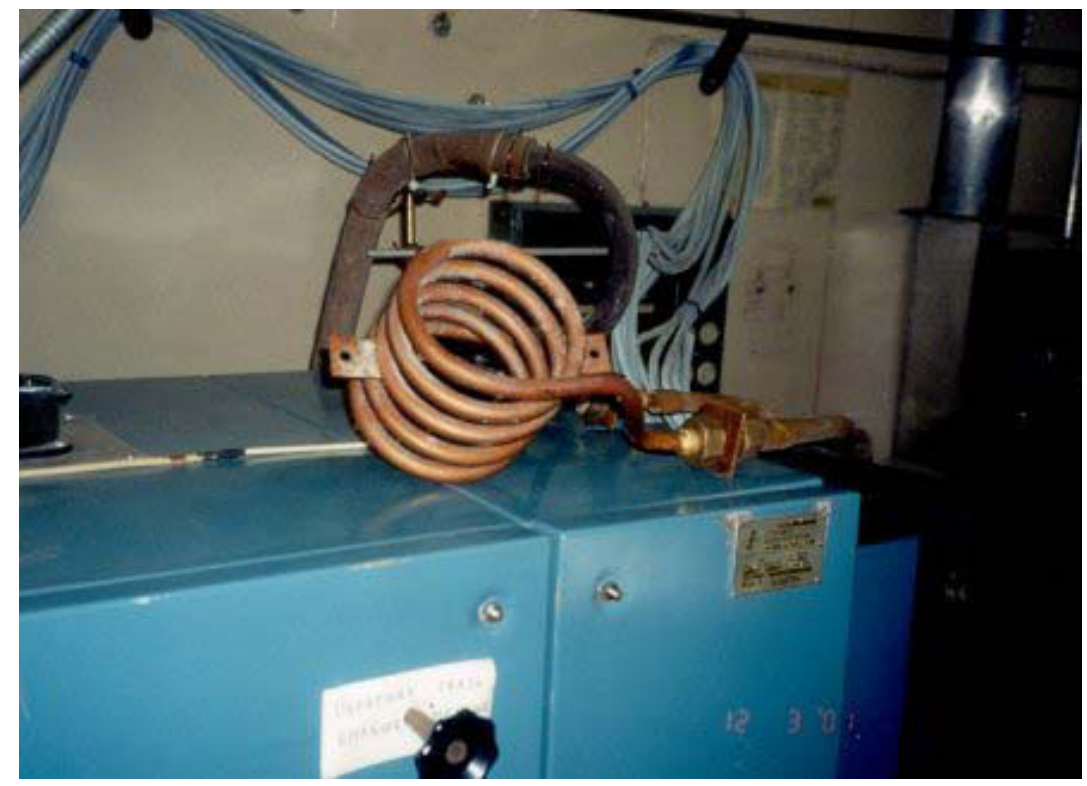

Figure 8. Induction Coil 


\section{Offgas Processing System}

Figure 9 illustrates the KRI five stage offgas processing system for their bench top melter. The offgas system is pictured in Figure 10. As can be seen in the figure and photograph, this is an analytical system, designed to capture samples for analysis and to test reagent for scrubbing efficiency. The system can capture readily condensable materials, VOCs, and particles in a static test, but the system is not scalable. Without the support of continuous feed or any ability to pour, this system cannot be used to quantify performance w/wo a cold-cap, entrainment, or destruction of organic constituents. Additional capabilities exist at St. Petersburg Elektrotechnical University, but the availability of equipment and support was not explored.

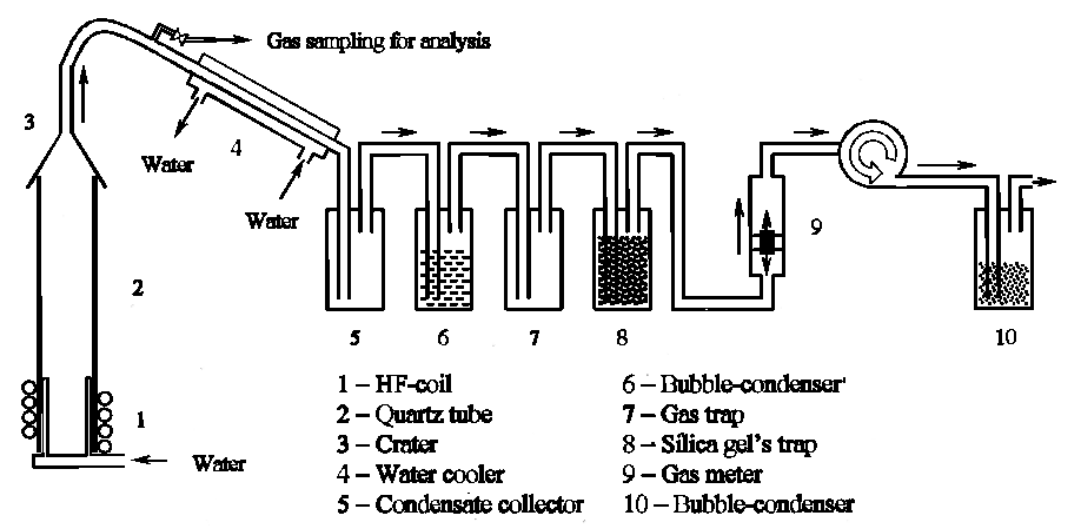

Figure 9. KRI Bench Top Offgas System Block Diagram

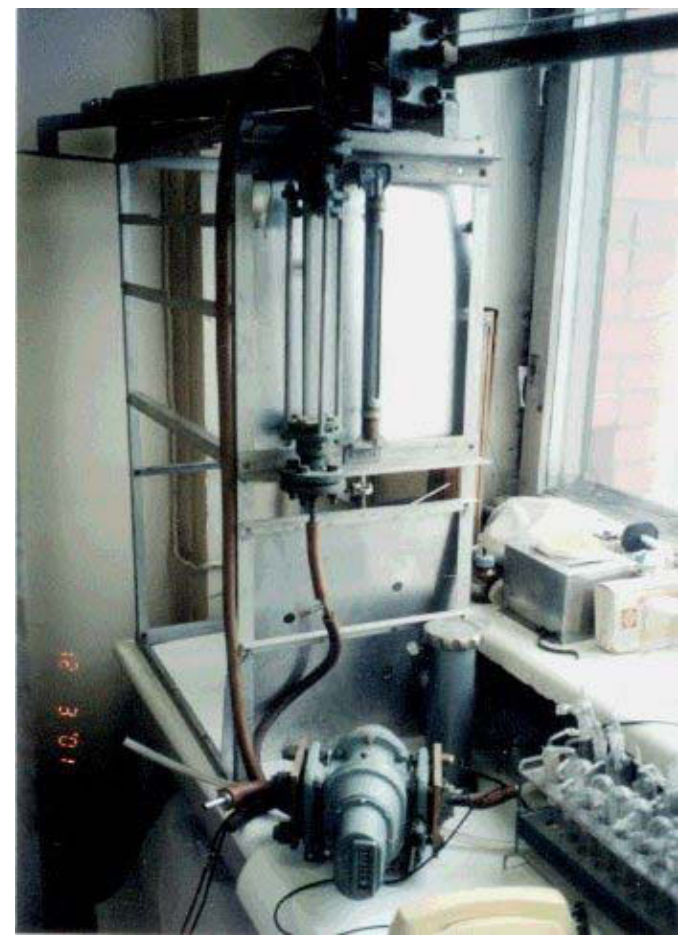

Figure 10. KRI Bench-top Melter Offgas System 


\section{Crucible Cooling System}

The external wall of the crucible is defined by a series of paired two-pass copper cooling tubes. There are fourteen of these tube channel pairs placed along a circular diameter of $17 \mathrm{~cm}$. Each loop has a top width of approximately $2 \mathrm{~cm}$. The loop spacing is approximately $2 \mathrm{~mm}$. See Figure 11 below. They are not configured in a serpentine, but are supplied with coolant water from a parallel manifold.
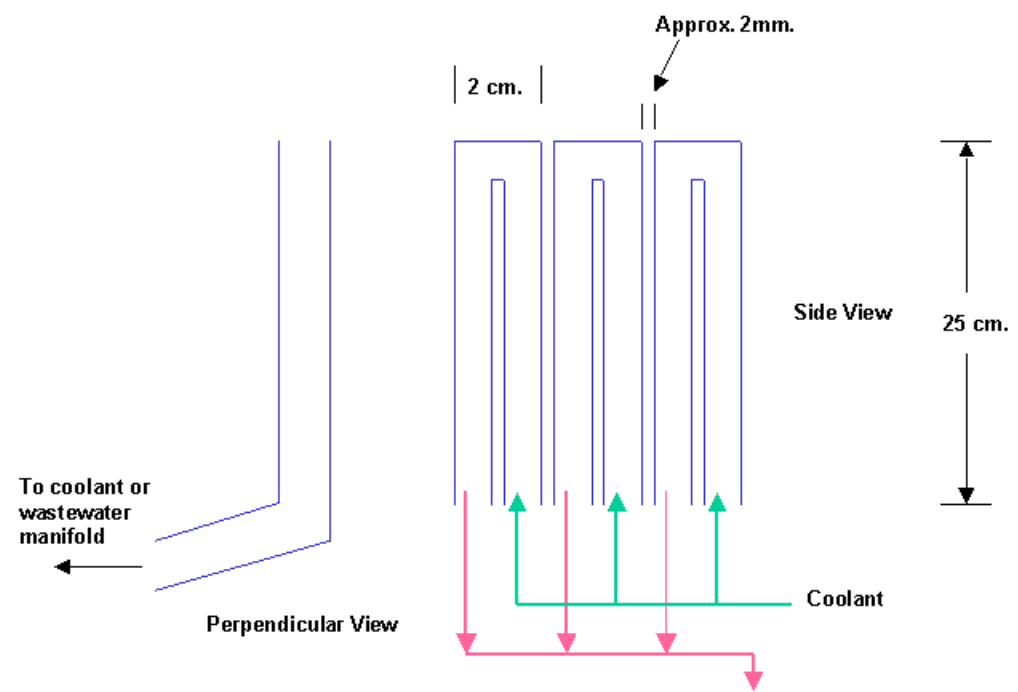

Figure 11. Cold Crucible Coolant - Tubes

Figure 12 is a photograph of the crucible assembly itself. Note the parallel coolant feed and return lines at the bottom. The cooling tubes themselves have an external diameter of $32 \mathrm{~mm}$. The entire assembly, including the feed to the wastewater manifold, is approximately $44 \mathrm{~cm}$ tall. Detailed dimensions are provided in Appendix B, KRI Crucible Dimensions.

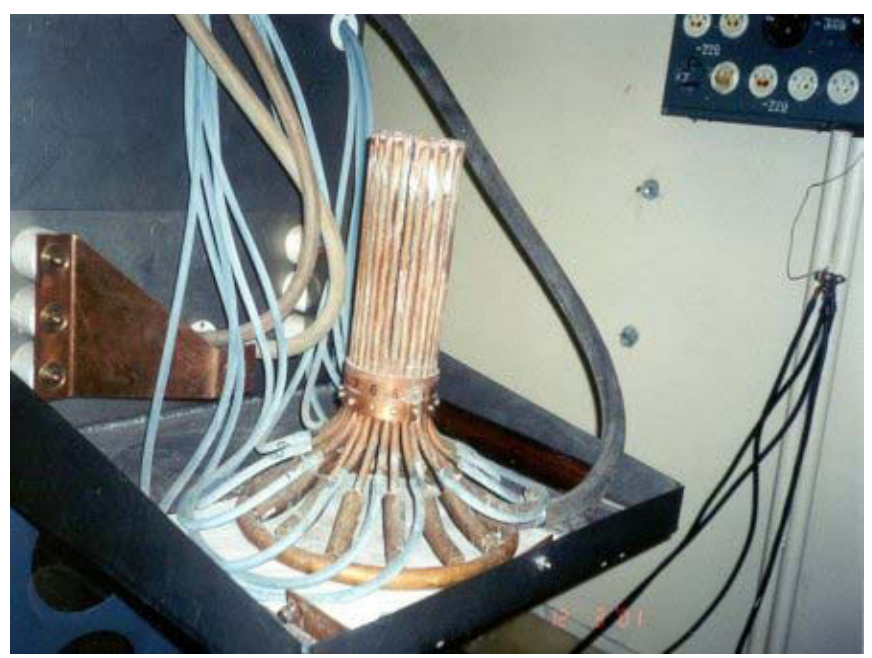

Figure 12. Cold Crucible Assembly with Cooling Supply Lines 
Figure 13 is a photograph of the supply manifold. Note that cooling water is supplied from the building water supply directly. This manifold also provides cooling to the RF generator power triode, and to the CCIM induction coil itself.

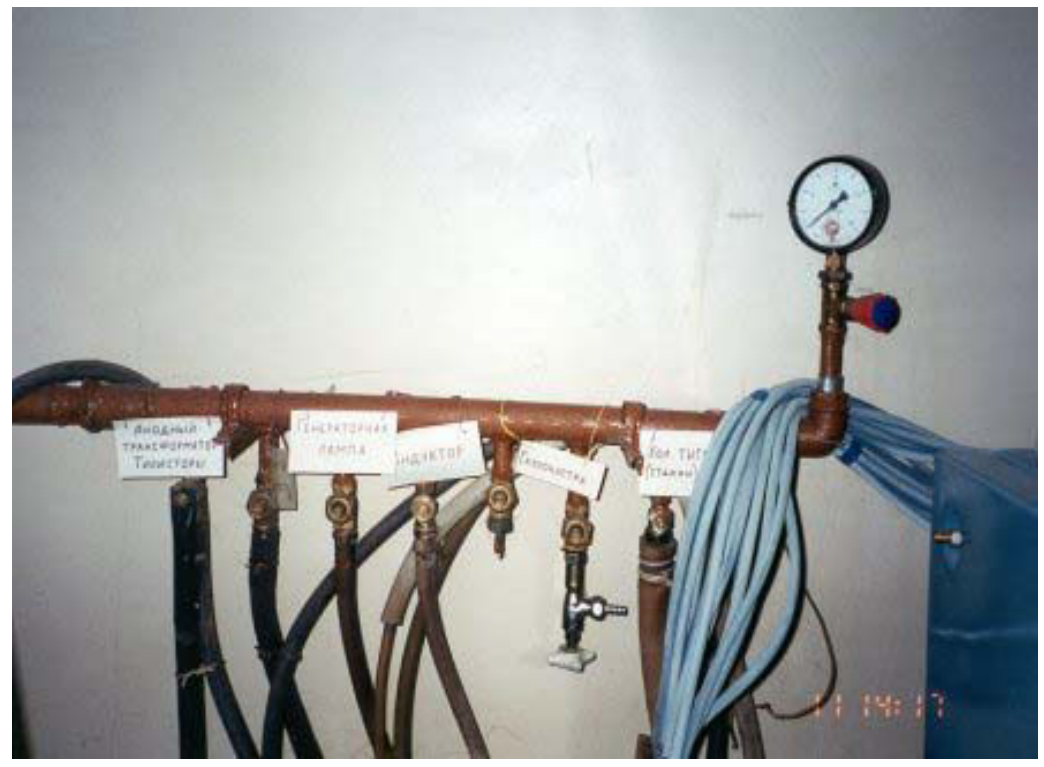

Figure 13. Cooling Manifold

\section{Melter}

Figure 14 is a photograph of the assembled KRI Cold Crucible Induction Melter. Note that the inductor is supported at approximately the vertical midpoint of the crucible assembly by two RF straps and a grounded center tap. The two straps conduct RF energy from the power oscillator to the coil. Also observe the horizontal collar assembly that contains the bottom plate.

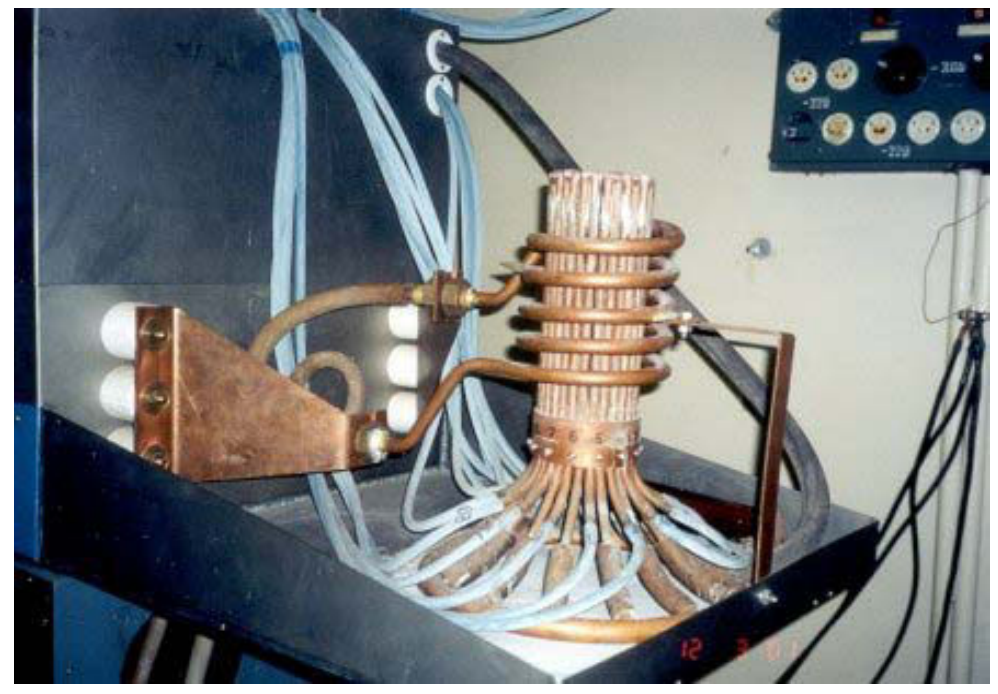

Figure 14. KRI Induction Melter 
Prior to operation of the KRI cold crucible induction melter system, the shielded assembly is placed around the CCIM inductor and crucible assembly. During operation the entire system is shielded. Figure 15 illustrates the system during an actual melter run that was performed during our visit.

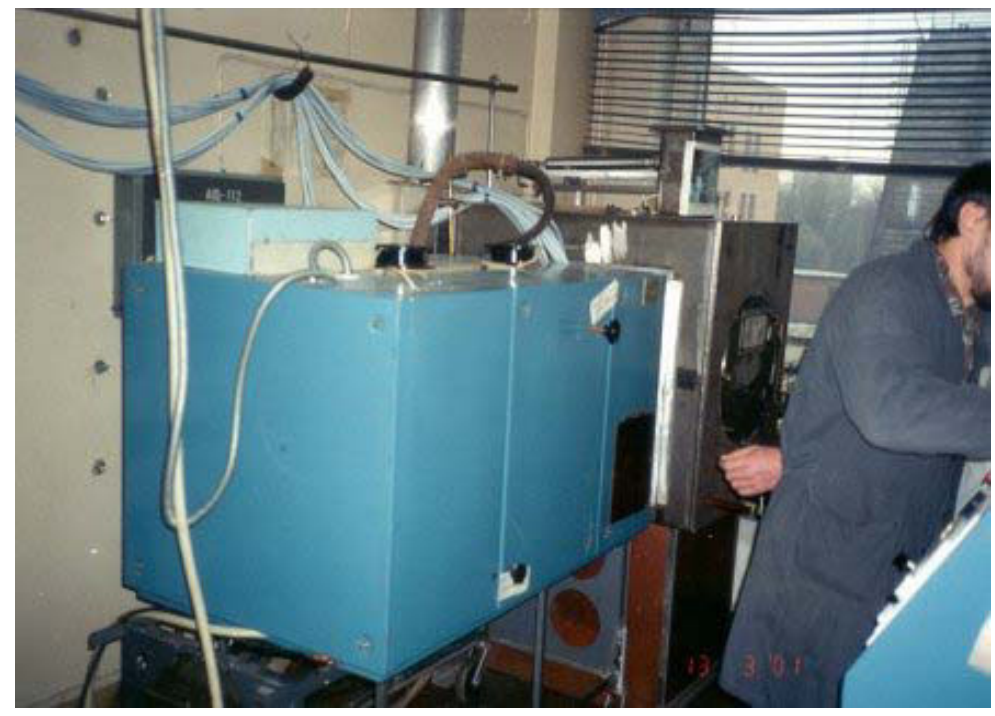

Figure 15. RF Unit and Melter in Operating Configuration

\section{Engineered Safety Systems}

There are a number of safety issues associated with operation of this type of bench top cold crucible melter. Many of these items also apply to a pilot of full scale CCIM facility.

1. Electrical: The RF generator unit and its associated power control system unit have electrical potentials in excess of 4 kilovolts. These are both direct and alternating current RF. In addition, there is three-phase power line potential in the power supply unit. The KRI system is not operated with any covers removed, and the assembled $\mathrm{RF}$ generator, power control unit, and CCIM are not operated unless all access doors are bolted closed and shielding is clamped in place. There are no exposed "hot" wires or bare cable connectors. Control is administrative and thus there are no electrical interlocks.

2. Radiated emissions: Radiated emissions are of concern due to the high RF fields generated by many kilowatts of energy at $1.76 \mathrm{MHz}$ being generated and transferred to the melter crucible. During operation the CCIM is enclosed in a shielded enclosure to reduce radiated emissions. See Figure 14. In Russia there is a radiated susceptibility human exposure standard, and laboratories working with this type of equipment are required by a regulatory agency to have an RF field survey done. This survey was done and summary results are in Appendix C, EMI Field Survey. In the United States whole body human radiated susceptibility is governed by ANSI/IEEE Standard C95.1 1991 (reaff. 1997), Standard for Safety Levels with Respect to Human Exposure to Radio Frequency Electromagnetic Fields, $3 \mathrm{KHz}$ to $300 \mathrm{gHz}$. 


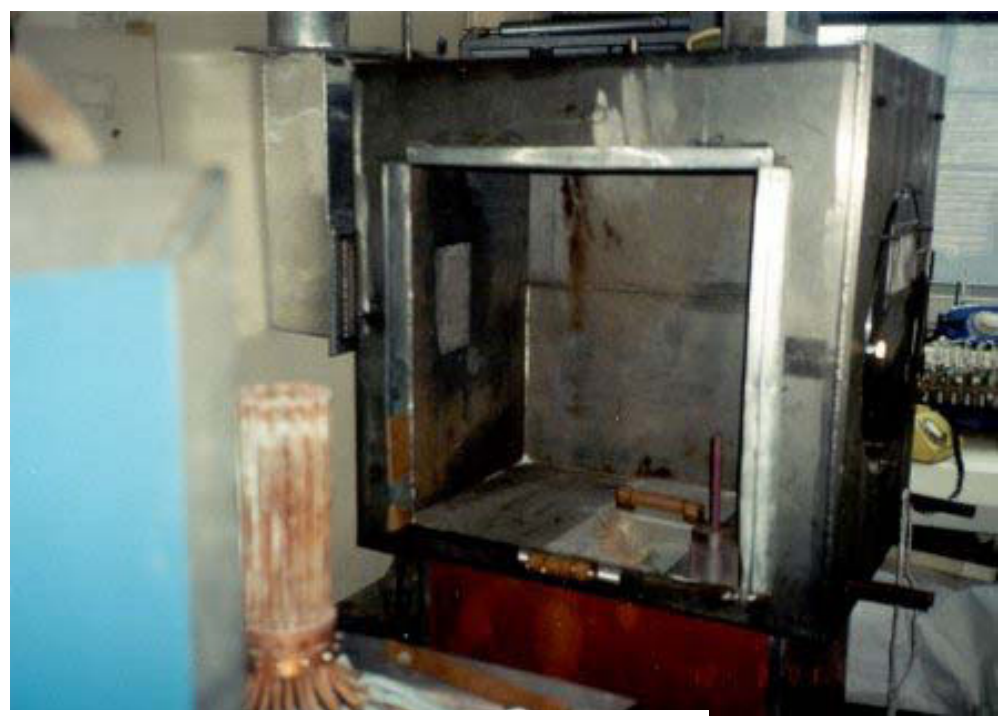

Figure 16. CCIM Shielded Enclosure

3. Crucible integrity: The physical integrity of the copper coolant lines forming the outer diameter of the crucible is easily lost if coolant is interrupted. The result could be a rapid evaporation of remaining coolant water locally and a steam explosion, possibly ejecting molten melt from the crucible. As described earlier, coolant is supplied through a manifold connected to a wall faucet and conducted through rubber hoses to the coolant assembly. It would be desirable to have a redundant coolant supply system and a containment around the crucible. At the KRI there does not appear to be a redundant water supply, but they do place an RF shield that fully encloses the crucible assembly. See Figure 14 above. It appears to be constructed of 0.05 in. stainless steel sheet (roughly equivalent of U. S. 18 gauge) and would probably suffice as a secondary physical containment if required. Certainly an upgraded system could include a segmented metallic crucible (imagine the staves of a wooden barrel) with the coolant tubing welded or brazed externally. An emergency water supply, and an interlock between crucible wall temperature or exiting water with the power source could be also be considered.

4. Offgas: The bench top system we observed is used to experimentally process nonhazardous surrogate materials. As described above, this system is designed to obtain analytical samples and is not suitable for scale-up or for processing significant amounts of toxic materials such as mercury, nitrates, or combustible halogenated solvents. Upgrade of the offgas treatment capabilities would be an area of emphasis if future laboratory support is to be conducted at the KRI.

\section{Experiments}

In support of the current LDRD project, the KRI will conduct three melts each with the borosilicate baseline and a new iron-phosphate glass formulation. The three melts will contain 33,38 and $42 \mathrm{wt} \%$ waste oxides using the Run 78 zirconia calcine composition provided by HLW Operations personnel. Three samples will be taken from each melt for leaching using the PCT protocol. Up to seven samples will be taken from each melt for x-ray diffraction. The eighteen PCT results and 42 XRF results will allow us to compare the two types of glass and evaluate homogeneity. During the startup, operation and shutdown of the melter, current and power data will be taken to characterize electrical performance to support our engineering 
analysis of the system. A novel startup technique using iron fragments or filings will also be used to see if the iron will support cold startup without producing offgas, then dissolve into the glass rather than being encapsulated as droplets.

If desired by Operations, the focus can be shifted to sodium bearing waste, but direction must be given soon, or laboratory resources will be wasted on the calcine work.

\section{Future Work}

The scope of the current LDRD is limited to exploration of the CCIM technology, and the potential for using iron-phosphate glasses for vitrification of INEEL HLW. One of the greatest benefits of this work is to conduct a fairly detailed review of the technology from an electrical engineering perspective. The final report will include this analysis, as well as recommendations on how to proceed if this technology is to be developed through pilot-scale to establish design parameters for implementation. Conceptually, any path forward will include 1) crucible studies for glass formulation testing, 2) laboratory-scale cold-crucible work to screen design concepts, and 3) pilot-scale development. Crucible studies could be done entirely in the USA, either at the INEEL, or with partial or complete contracting to SRS or PNNL. However, it seems likely that collaborative work with Russian researchers may be quite cost-effective. The laboratory-scale melter will be used to test design concepts including melter core configuration, pouring, and feed preparation. As desirable as it is to have this type of unit close at hand, it would probably form the basis for a strategic alliance to collaboratively design this unit with Russian expertise, adapted for our developmental plans, and to install it at the KRI. We have much more to learn from our Russian colleagues at this stage than they do from us, and building on this relationship to advance the current state-of-the-art is critical. The pilot-unit would be based on the lab-scale results, and would be designed to provide scaling factors for a full-scale implementation. 


\section{Contacts at RADON and KRI}

Dr. Sergey Stefanovsky

Scientific Director

Center of Advanced Technologies

SIA Radon

$7^{\text {th }}$ Rostovskii per. $2 / 14$

Moscow 119121 Russia

Itbstef@cityline.ru

(095) 919-31-94

Dr. Victor Vlasov

Albert Alloy

Head of Laboratory

V. G. Khlopin Radium Institute

$2^{\text {nd }}$ Murinskiy ave., 28

St. Petersburg, Russia

Aloy@atom.nw.ru

Dmitry Lopukh, PhD., Associate Professor

St. Petersburg Elektrotechnical University (LETI)

Prof. Popov Street 5

St. Petersburg 197376, Russia

Lopukh@mail.axon.ru 


\section{APPENDIX B:}

\section{KRI CRUCIBLE DIMENSIONS}

Note: All dimensions in millimeters

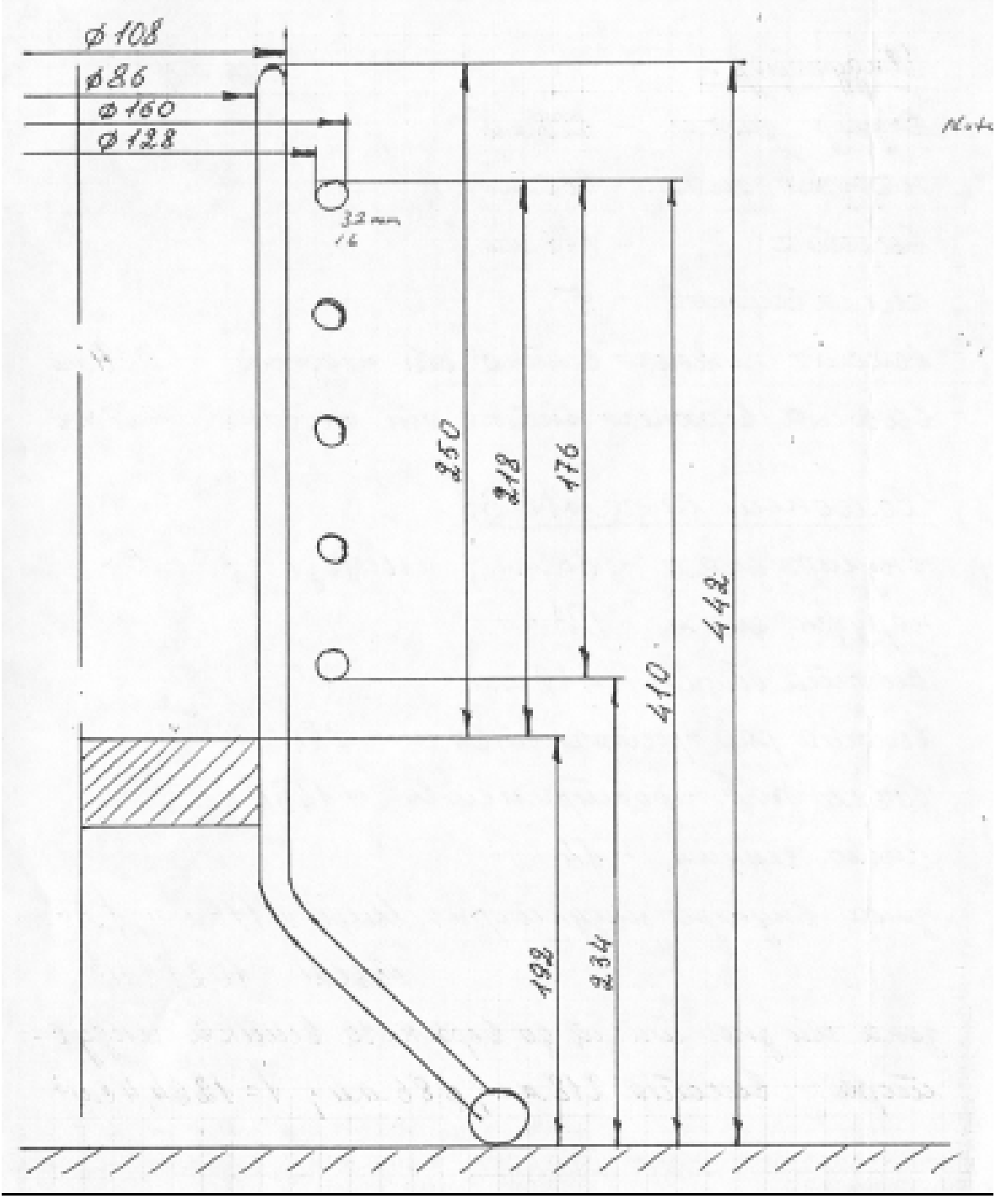


This Page intentionally left blank.

B-2 


\section{APPENDIX C:}

\section{KRI LAB EMI FIELD SURVEY}

As noted earlier, Russian regulators conducted an electromagnetic survey of the CCIM laboratory at KRI. The attached sheet is a copy of the survey results. It is in Russian. The upper part of the sheet is a plan view of the laboratory. The RF generator (labeled блок ВЧГ), inductor (labeled ИНДУКТОР), shielded melter enclosure and power control system are shown at the top of the drawing.

The measured field strengths are summarized in the table at the bottom. The ordinate contains two entries. The first entry indicates the inductor without the shielded enclosure in place. The second entry indicates the inductor with the shielded enclosure in place. This second entry reflect the normal operating mode of the CCIM system. The abscissa presents electric field in Volts per meter (labeled E; B/M) and magnetic field in Amps per meter (labeled H; A/M) at each of four locations in the laboratory room. The locations are identified by associated numbers at the top of the table and on the plan view of the lab layout.

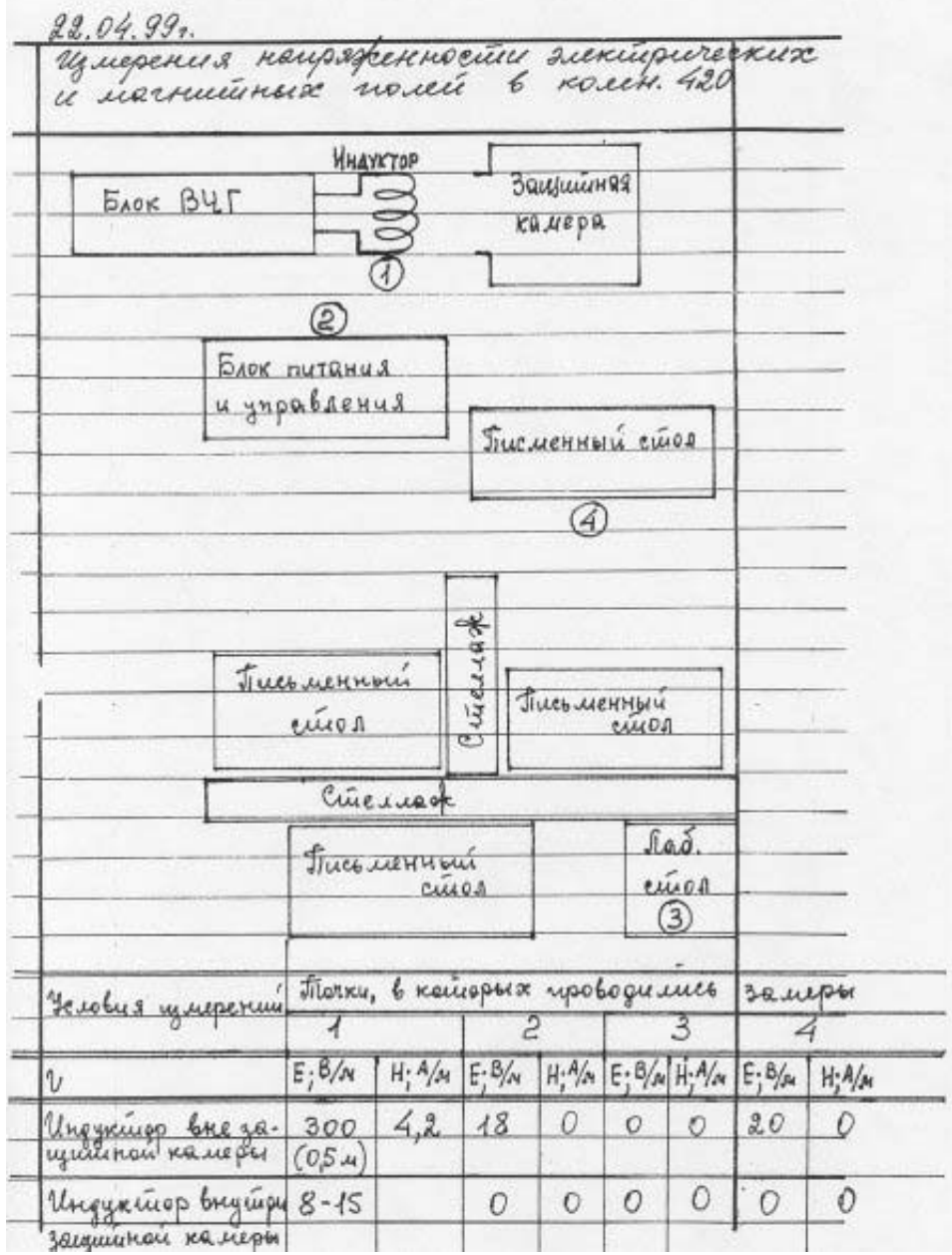


This Page intentionally left blank.

C-2 


\section{APPENDIX D:}

SCHEMATIC OF LAMP GENERATOR AND CCI INDUCTOR COUPLING NETWORK

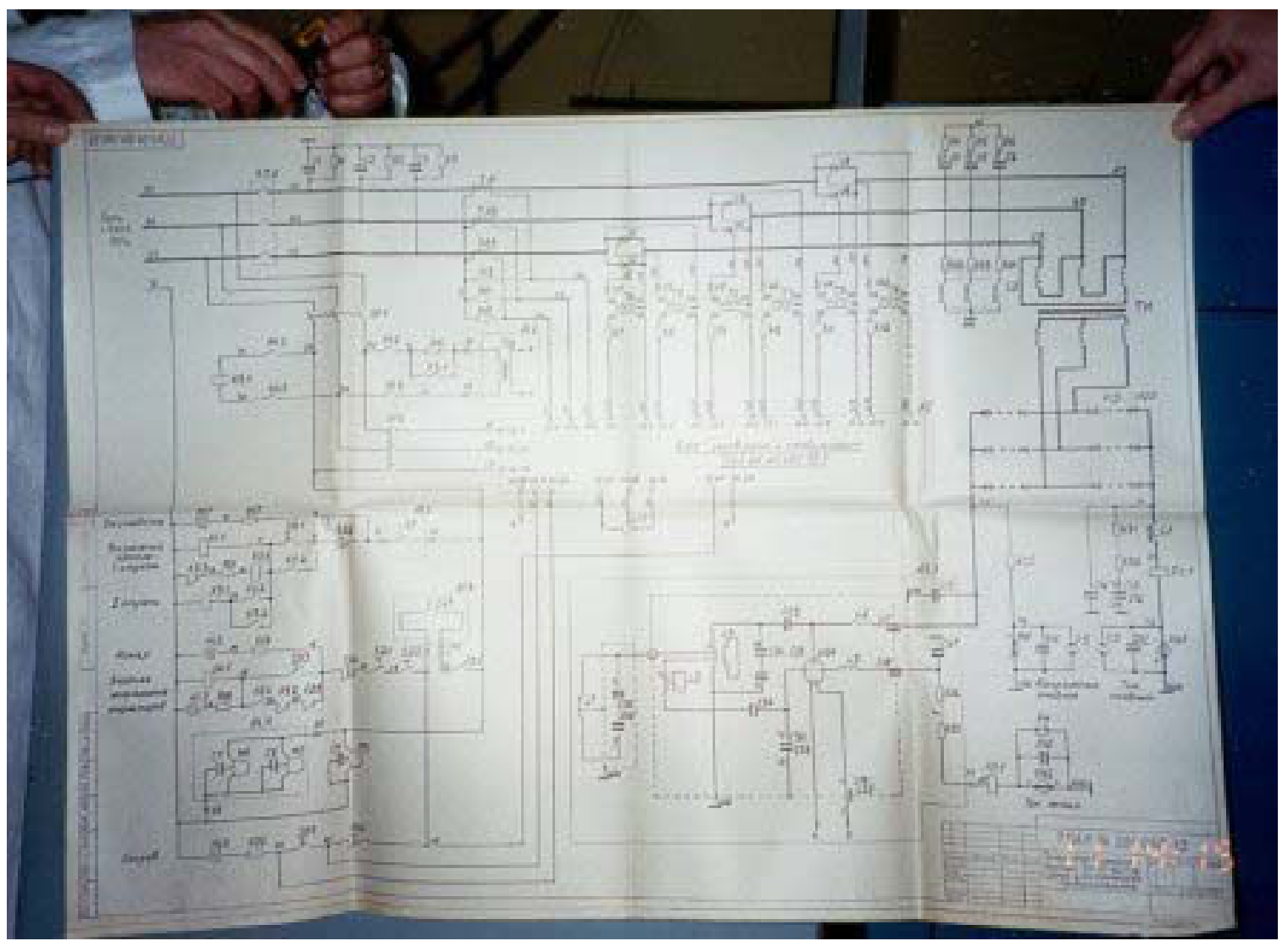

